\title{
One-Pot Transformation of Hypervalent Iodines into Diversified Phenoxazine Analogues as Promising Photocatalysts
}

Jiajia Cheng, ${ }^{*}$ Liangsen Huang, Hongxiang Xiao, and Shulin Jiang

State Key Laboratory of Photocatalysis on Energy and Environment, Key Laboratory of Molecule Synthesis and Function Discovery (Fujian Province University), College of Chemistry, Fuzhou University, 2 Xueyuan Road, Fuzhou 350116, P. R. China

jjcheng@,fzu.edu.cn

Table of contents

1. Set-up of the Photoredox-catalyzed Reactions............................................... 22

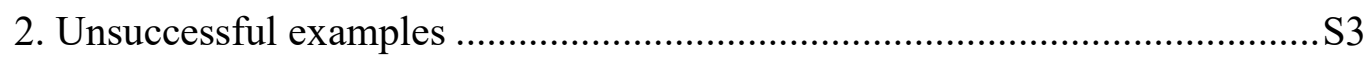

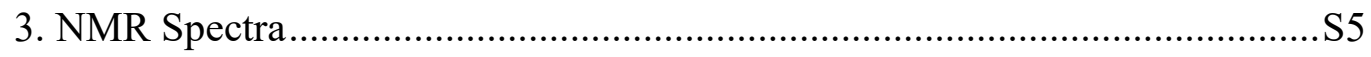

4. NMR and GPC Spectra of the Photoredox-catalyzed Atom Transfer Radical Polymerization S59 


\section{Set-up of the Photoredox-catalyzed Reactions.}

Photo-induced reactions were conducted in photo-reactors (Wuhan Keao Chem, Inc., Wuhan, China), which comprise a fan for cooling (approximately room temperature) and six $1 \mathrm{~W}$ white LED beads for each place $(6 \mathrm{~W})$. The reaction vial was suspended about $1 \mathrm{~cm}$ above the LED beads. The average power output of the photo-reactor was ca. $30 \mathrm{~mW} / \mathrm{cm}^{2}$.

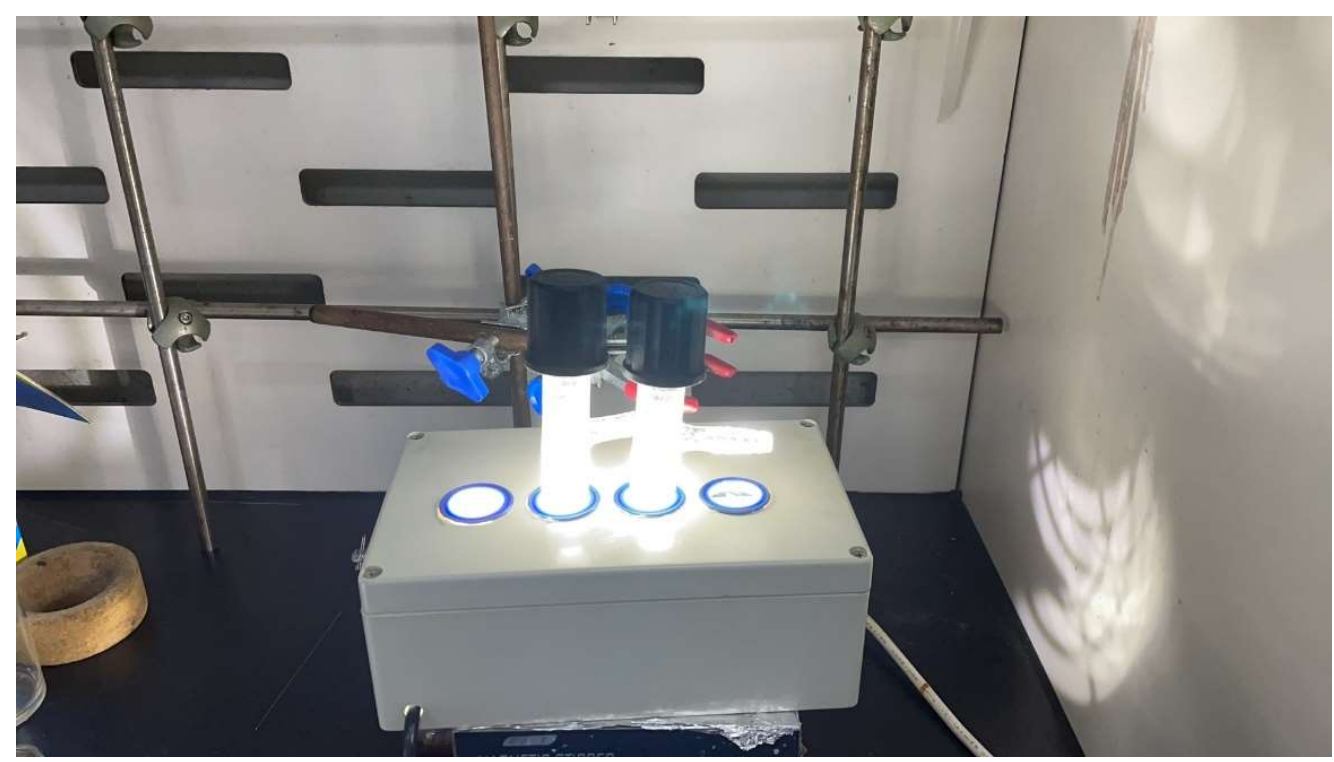

Figure S1. Set-up of the photoredox-catalyzed reactions. (Photographed by Liangsen Huang) 


\section{Unsuccessful examples.}<smiles>Oc1ccnc2ccccc12</smiles><smiles>CC(=O)OI(OC(C)=O)c1ccccc1Br</smiles><smiles>Brc1ccc(N2c3ccccc3Oc3c2cnc2ccccc32)cc1</smiles>

trace product<smiles>COC(OC(C)=O)OC(C)=O</smiles>

trace product

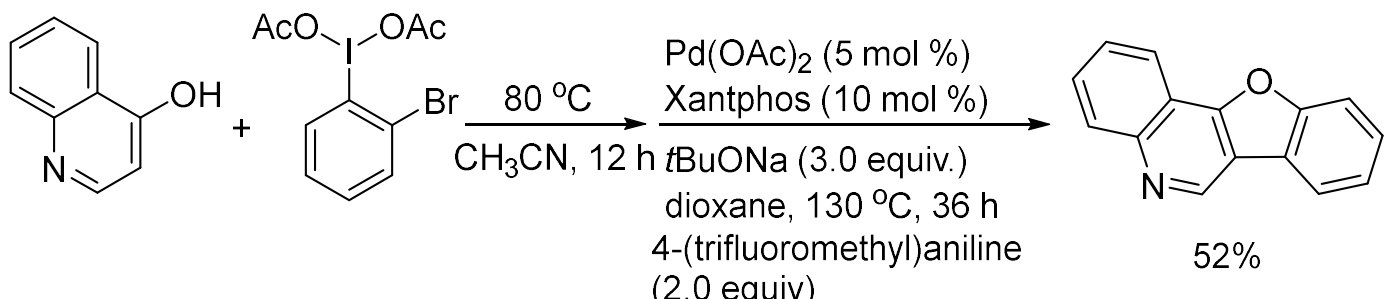
(2.0 equiv)

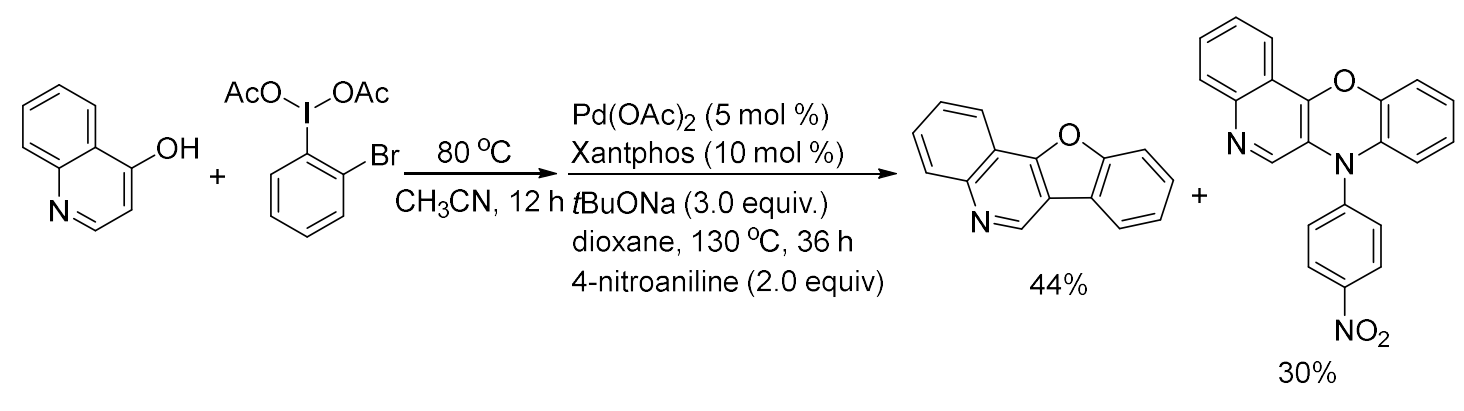<smiles>COC(=O)c1ccc(O)cc1</smiles>
trace product 


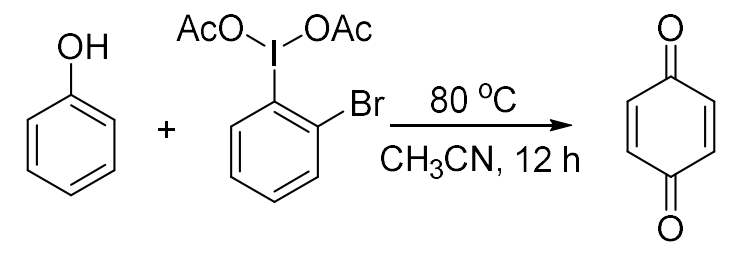

main product

S4 


\section{NMR Spectra.}

${ }^{1} \mathrm{H}$ NMR $\left(400 \mathrm{MHz}, \mathrm{CDCl}_{3}\right)$ spectrum of $\mathbf{4 a}$

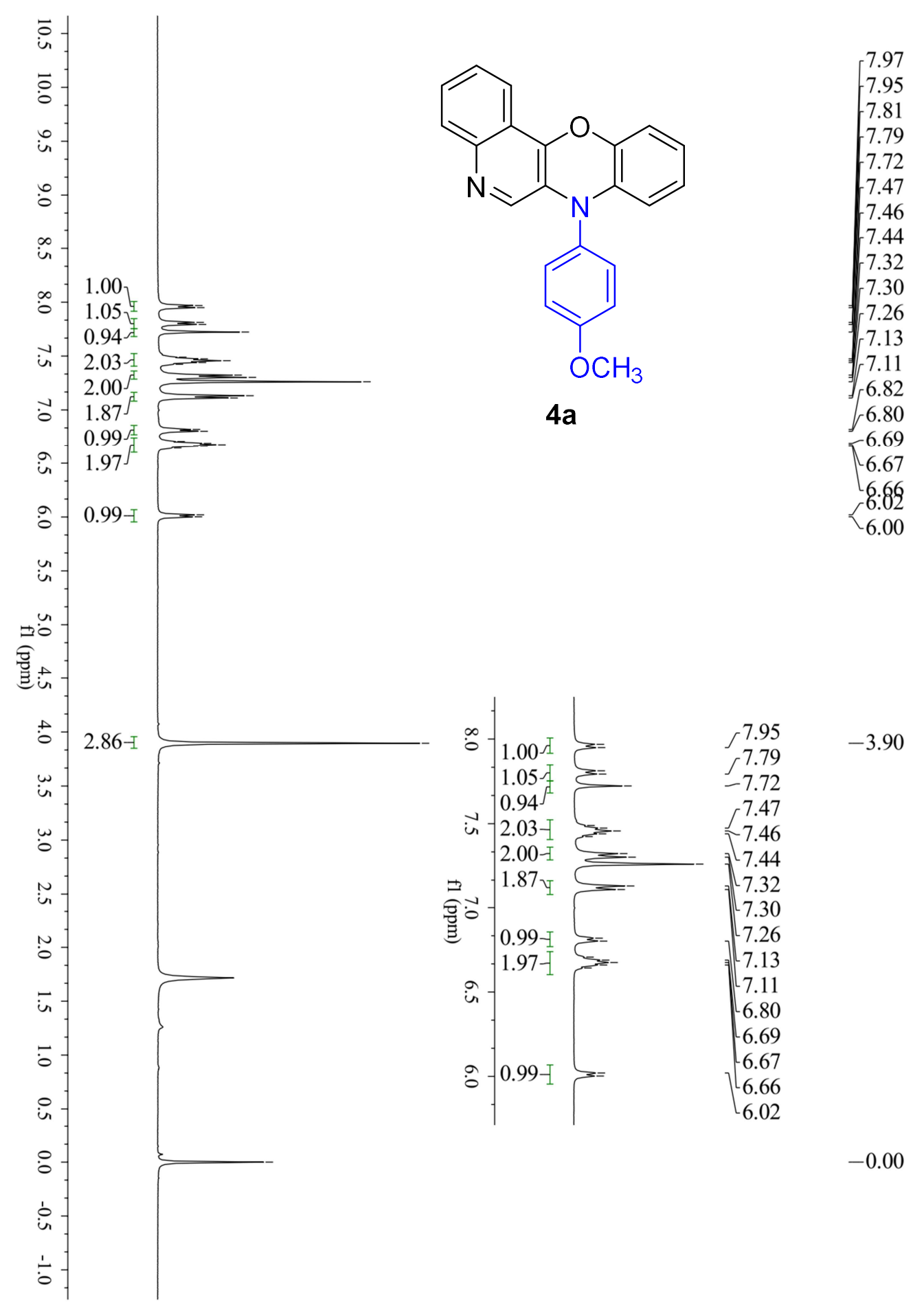




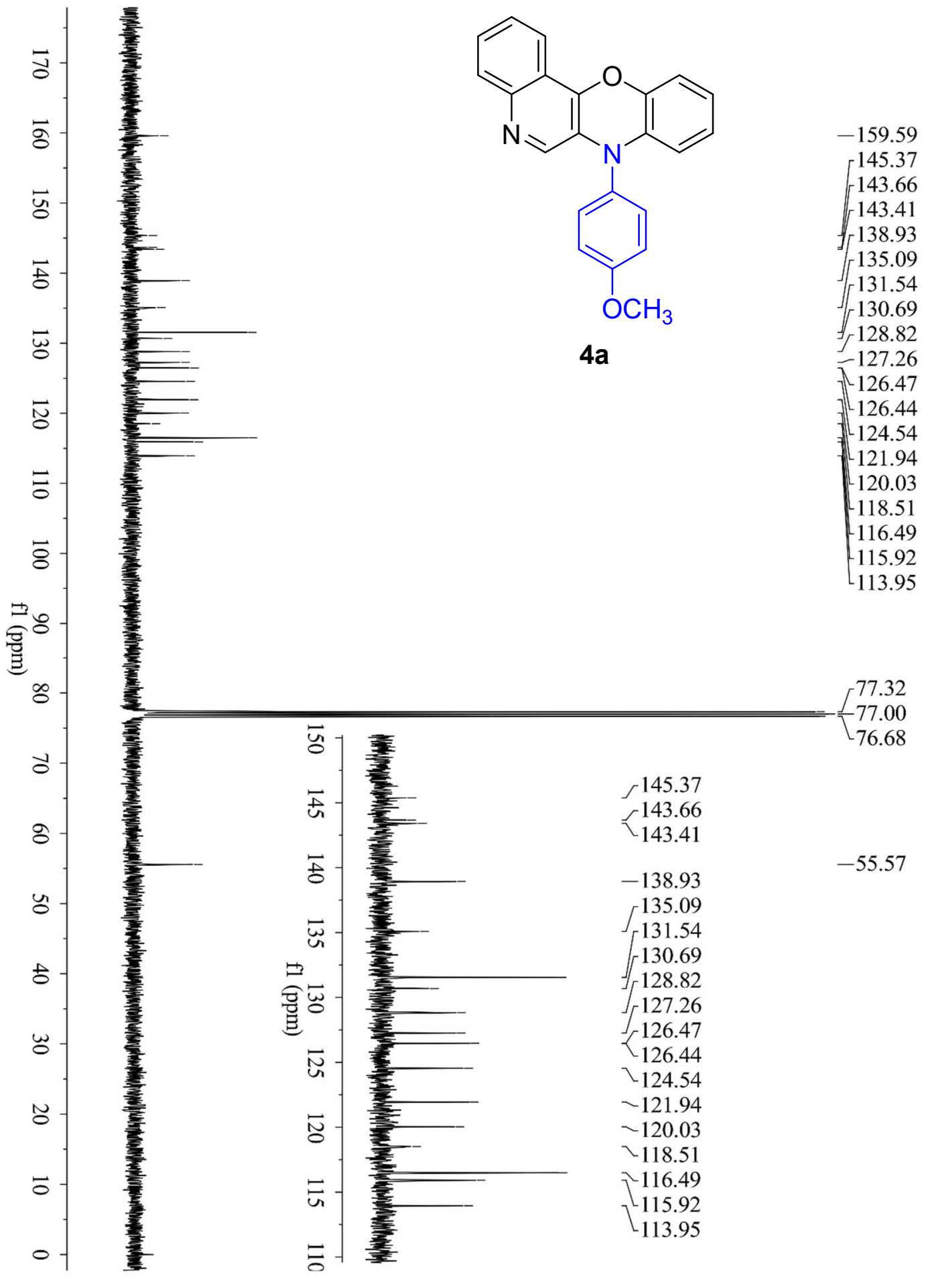


${ }^{1} \mathrm{H}$ NMR (400 MHz, $\mathrm{CDCl}_{3}$ ) spectrum of $\mathbf{4 b}$
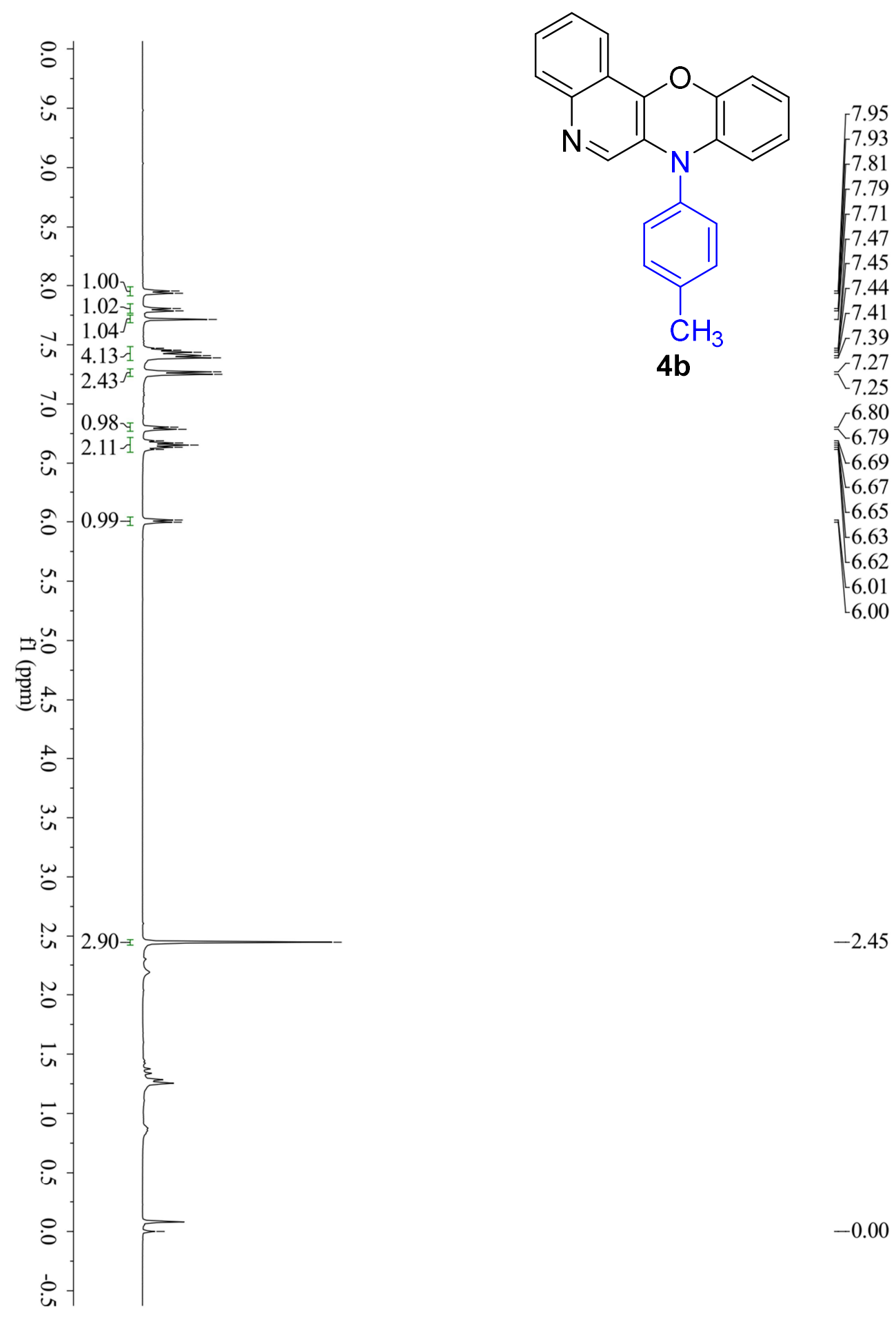


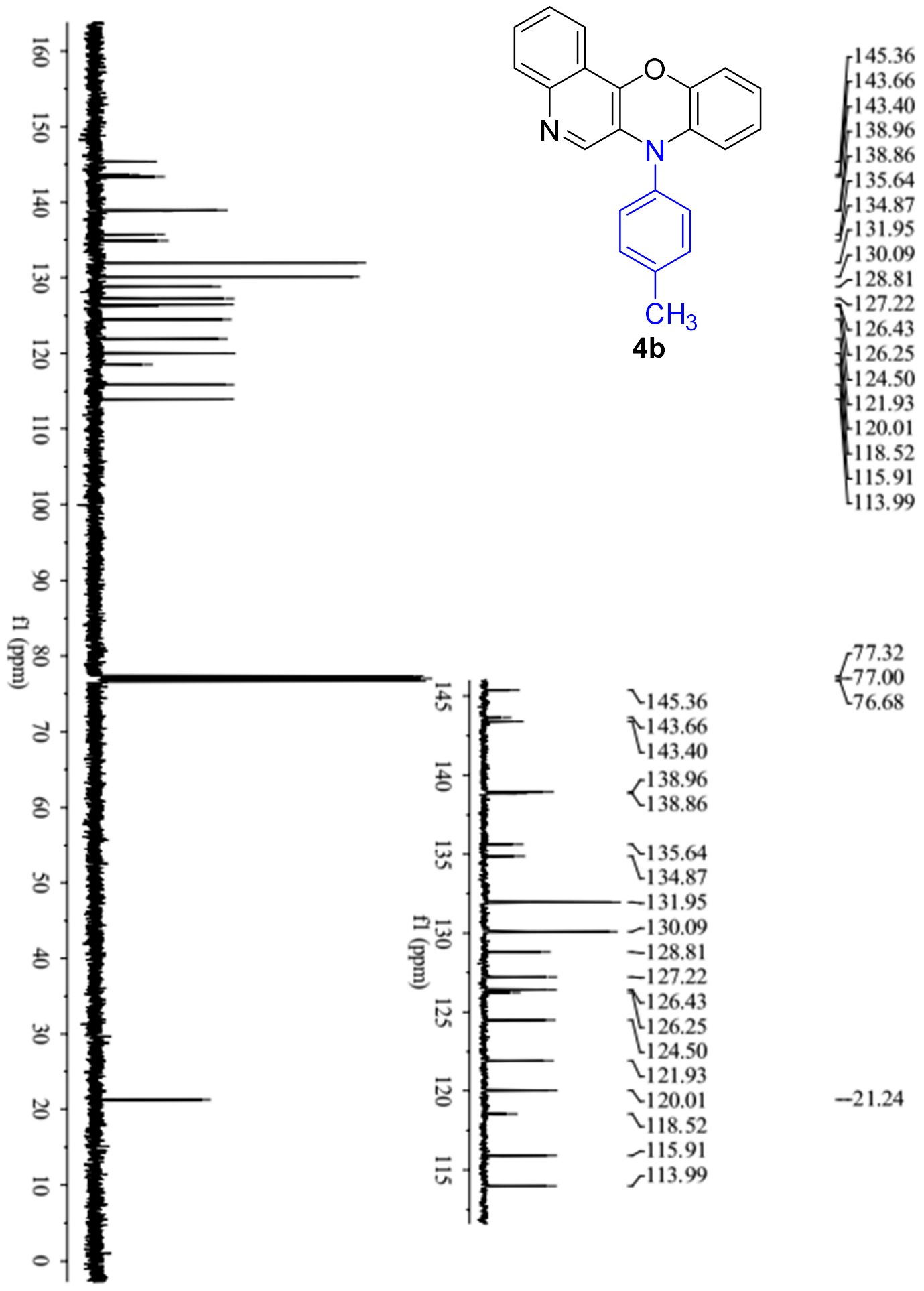


${ }^{1} \mathrm{H}$ NMR (400 MHz, $\mathrm{CDCl}_{3}$ ) spectrum of $\mathbf{4 c}$

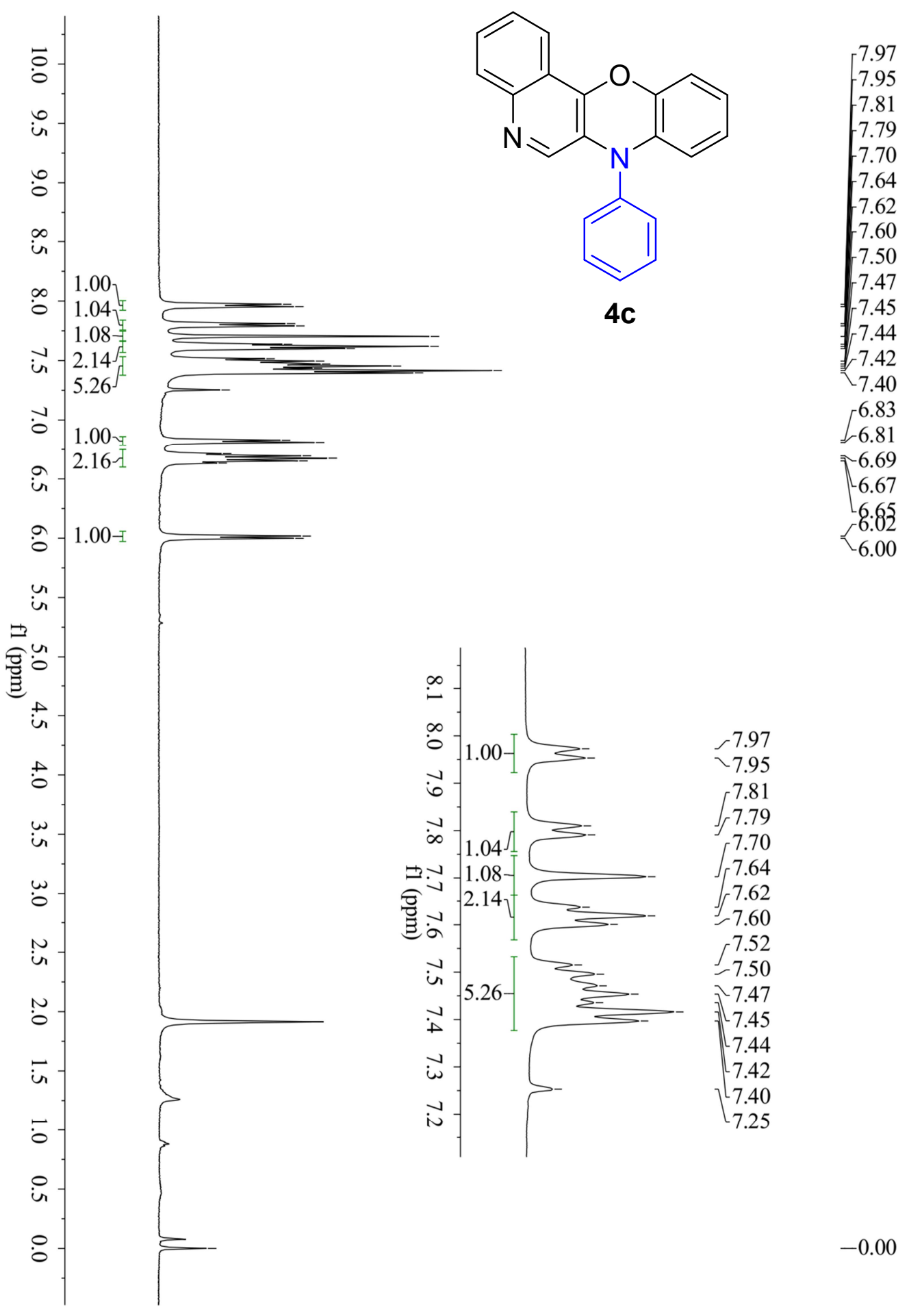




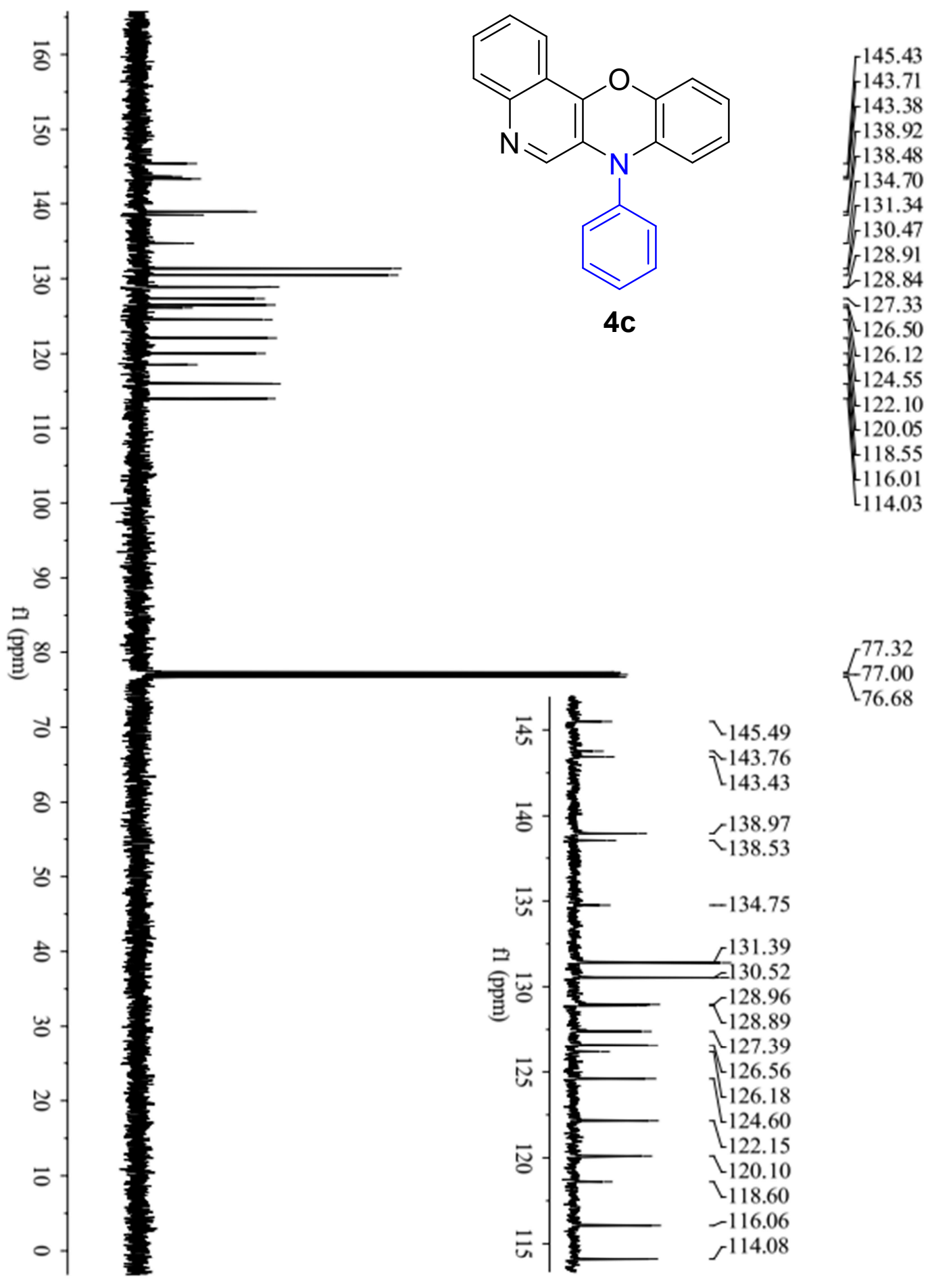


${ }^{1} \mathrm{H}$ NMR (400 MHz, $\mathrm{CDCl}_{3}$ ) spectrum of $\mathbf{4 d}$
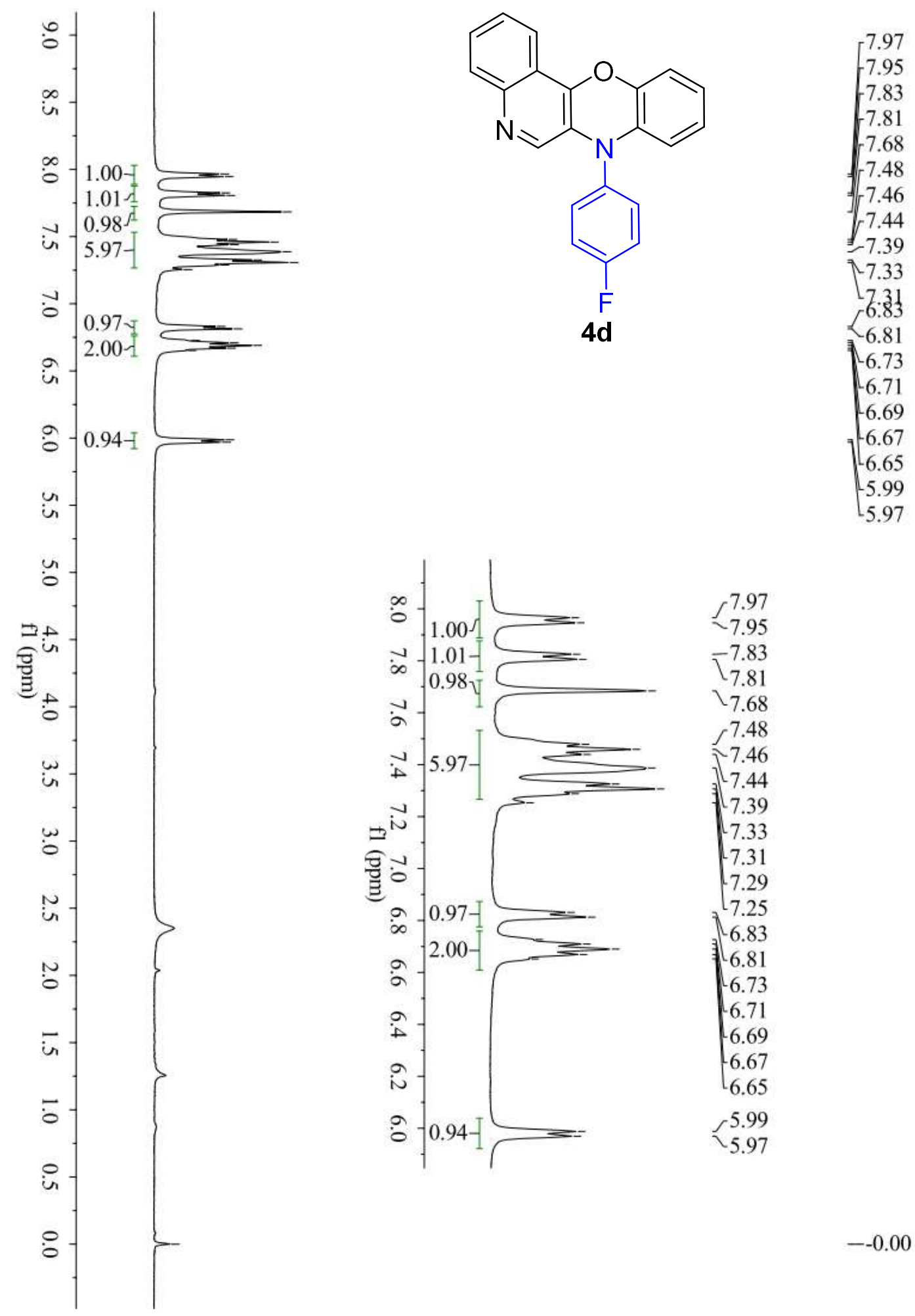

$--0.00$ 
${ }^{13} \mathrm{C}\left\{{ }^{1} \mathrm{H}\right\}$ NMR $\left(101 \mathrm{MHz}, \mathrm{CDCl}_{3}\right)$ spectrum of $\mathbf{4 d}$

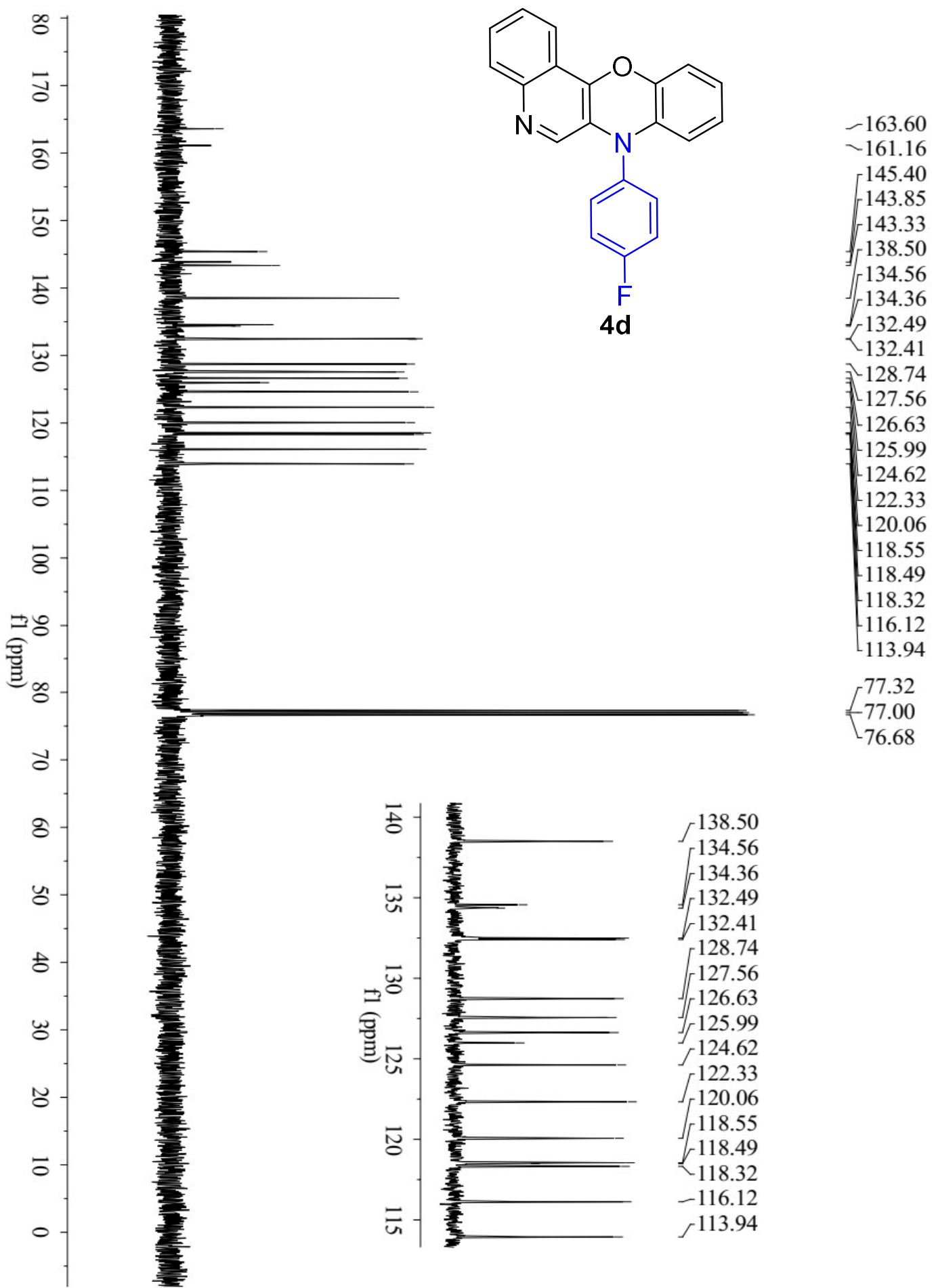


${ }^{19} \mathrm{~F}$ NMR (376 MHz, $\mathrm{CDCl}_{3}$ ) spectrum of $\mathbf{4 d}$

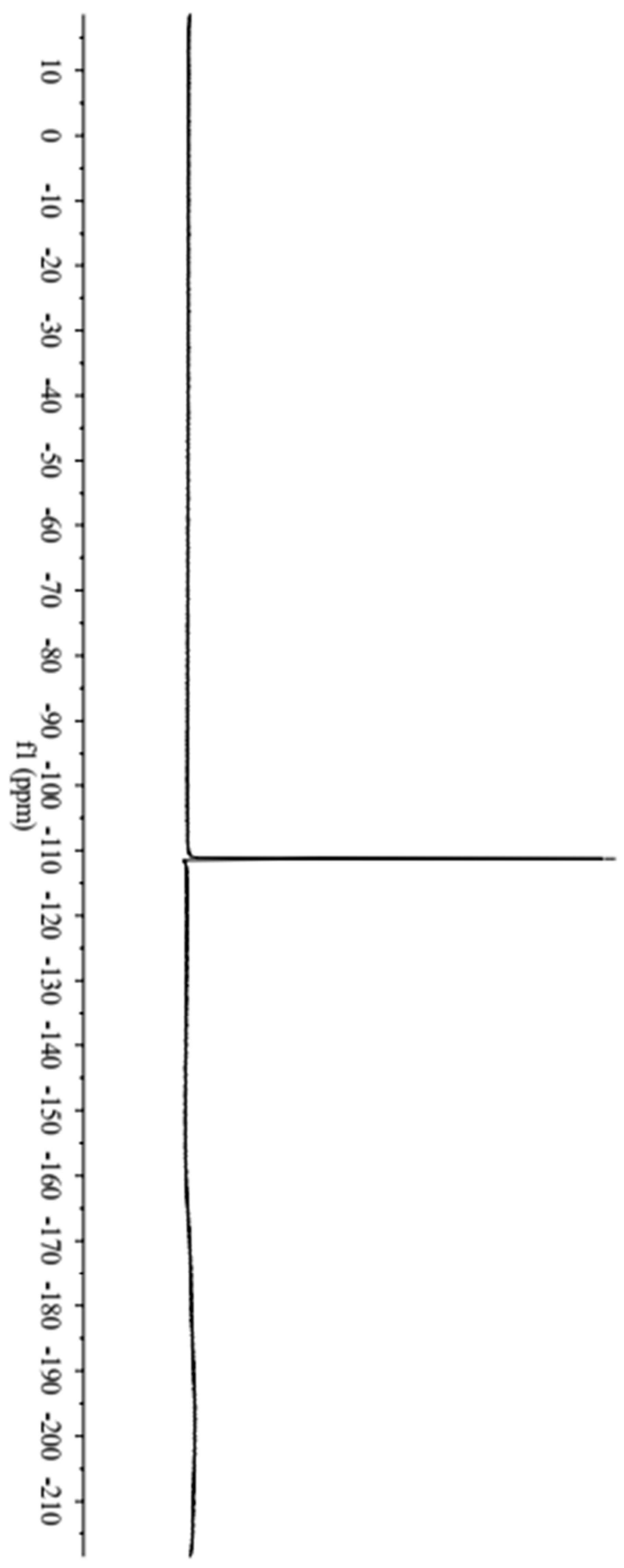


${ }^{1} \mathrm{H}$ NMR (400 MHz, $\mathrm{CDCl}_{3}$ ) spectrum of $\mathbf{4 e}$
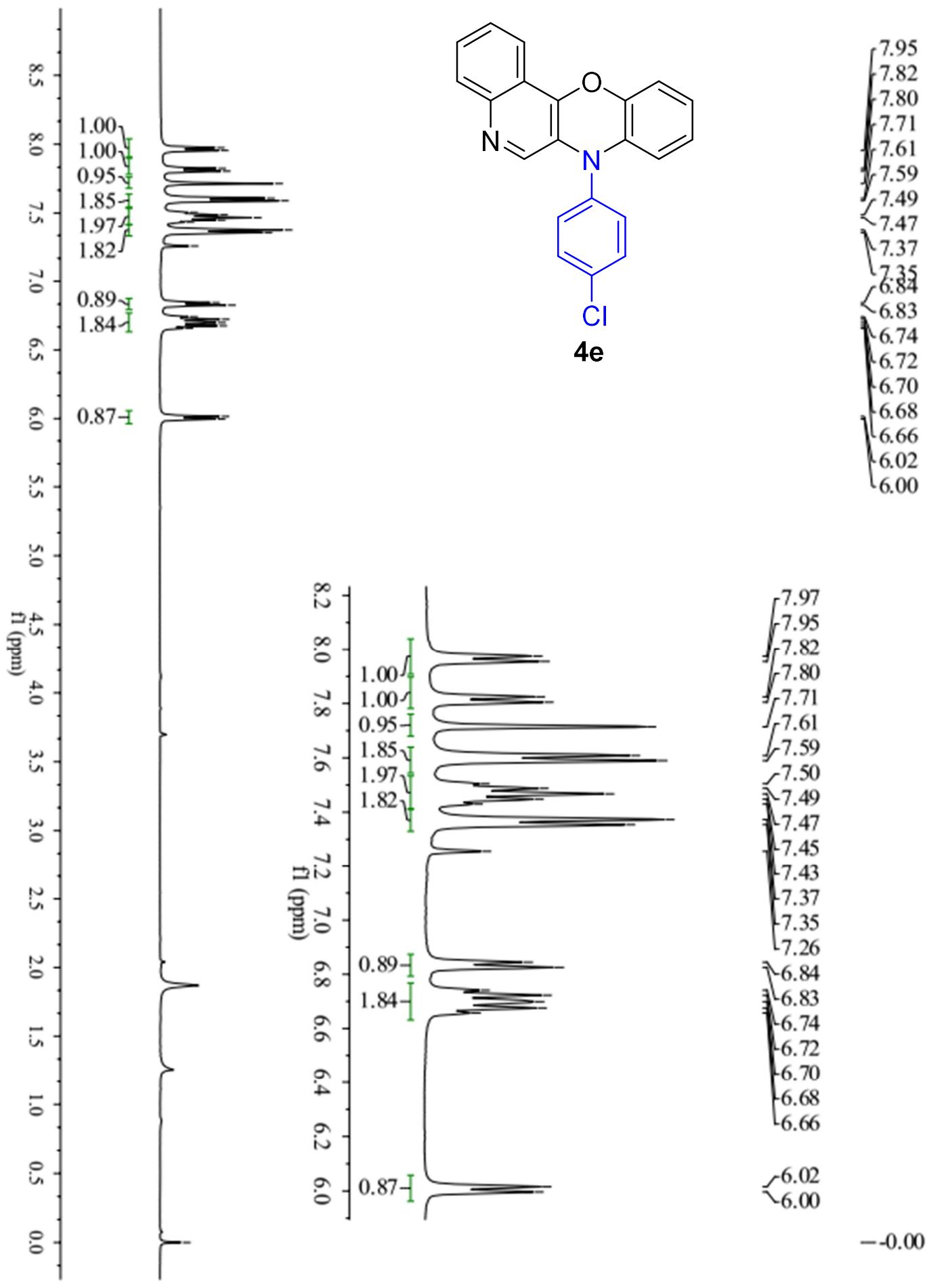
${ }^{13} \mathrm{C}\left\{{ }^{1} \mathrm{H}\right\}$ NMR $\left(101 \mathrm{MHz}, \mathrm{CDCl}_{3}\right)$ spectrum of $\mathbf{4 e}$

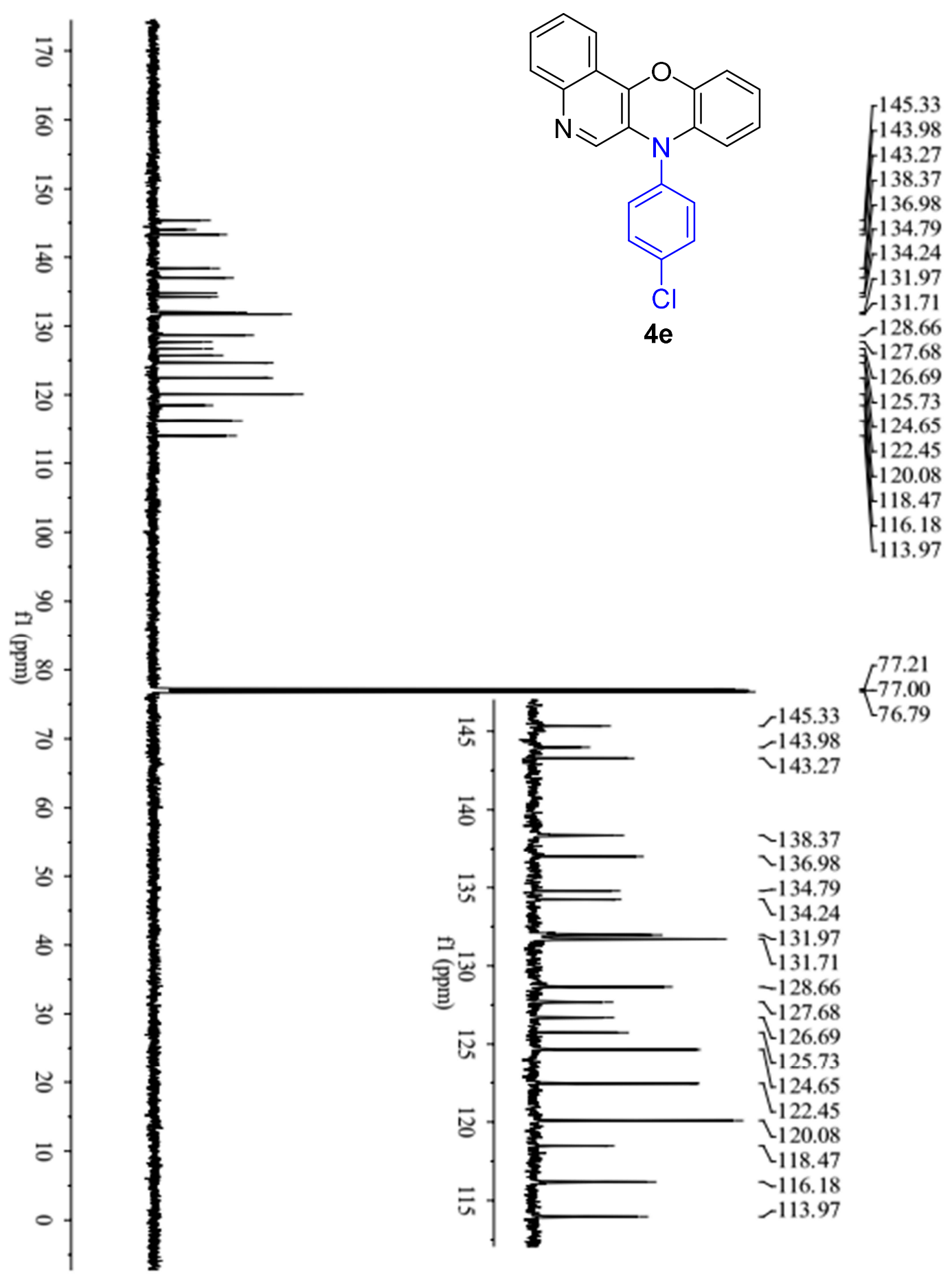


${ }^{1} \mathrm{H}$ NMR (400 MHz, $\mathrm{CDCl}_{3}$ ) spectrum of $\mathbf{4} \mathbf{f}$

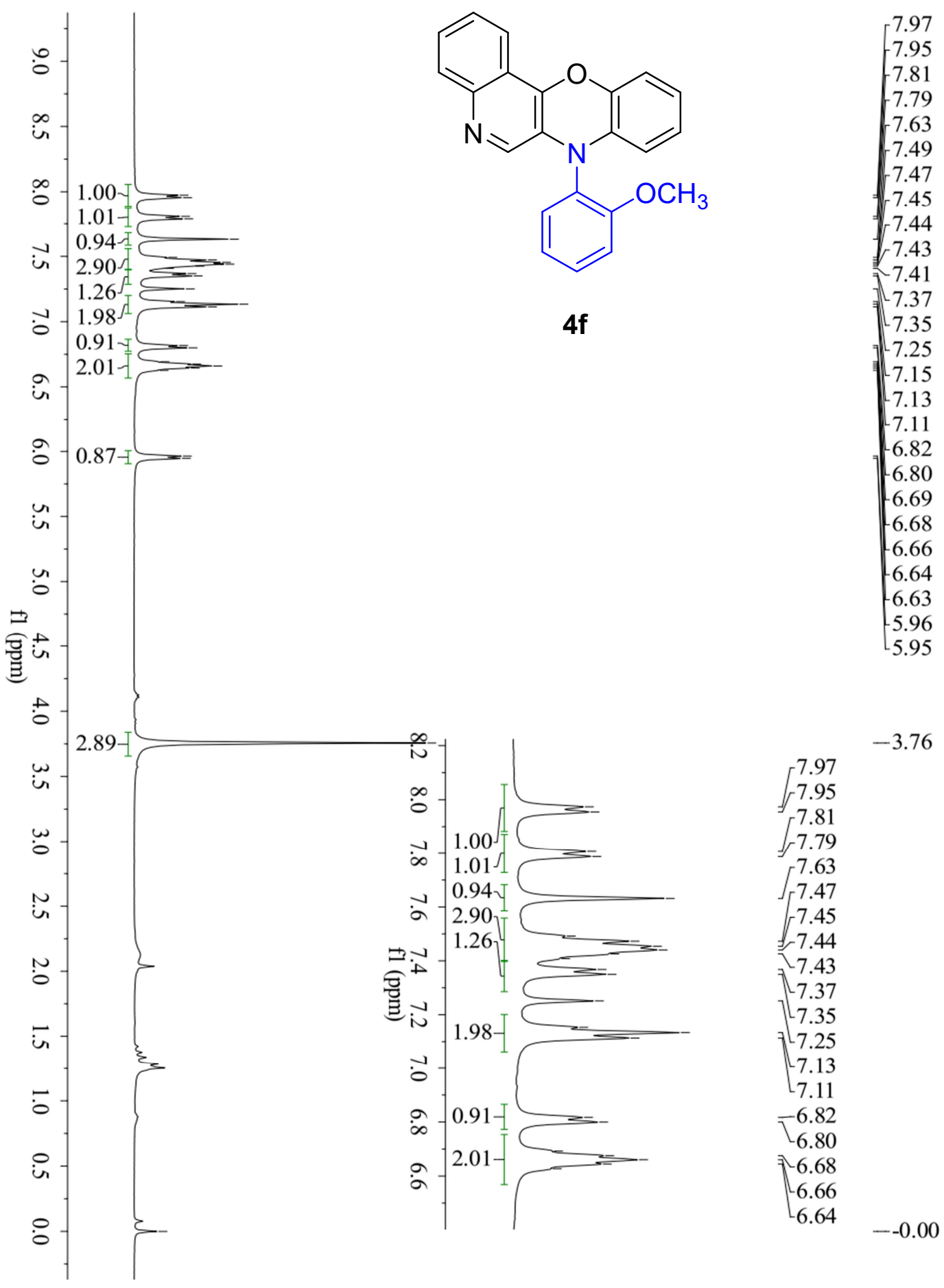




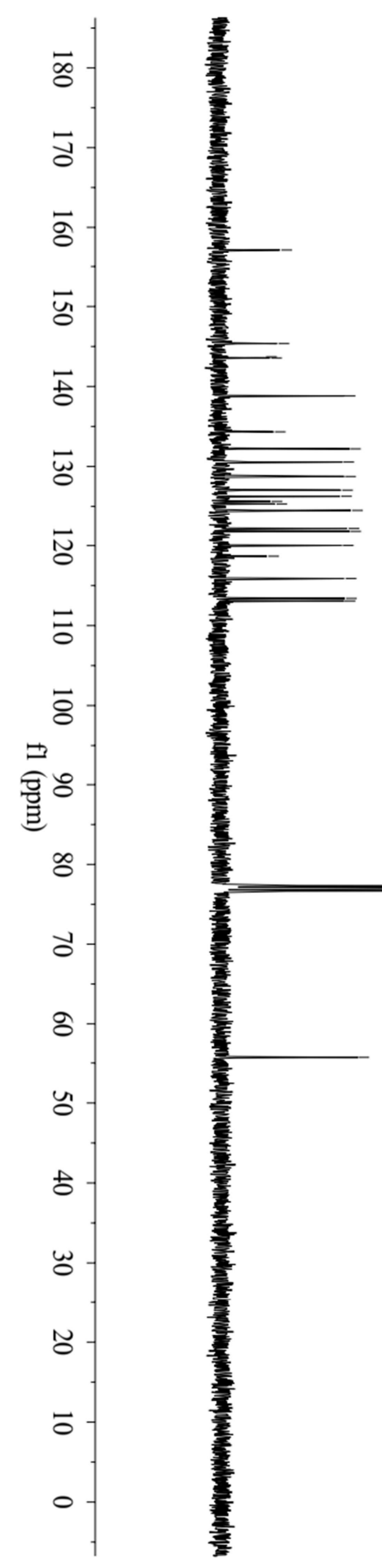<smiles>COc1ccccc1N1c2ccccc2Oc2c1cnc1ccccc21</smiles>

-157.16
$\int_{145.36}^{143.72}$
-143.56

138.81

134.33

132.20

$-130.55$

128.74

127.04

126.27

$-125.63$

$-125.31$

$-124.50$

$-122.14$

$-121.78$

$-120.02$

118.67

$-115.88$

$-113.39$

113.07

$-138.81 \quad\left[\begin{array}{l}77.32 \\ 77.00 \\ 76.68\end{array}\right.$
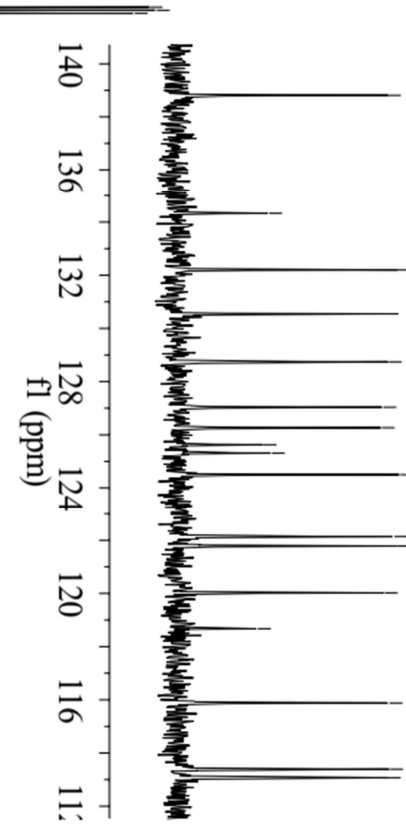

$-138.81$

$-76.68$

$-134.33$

$-55.70$

132.20

130.55

128.74

126.27

125.63

$-125.31$

124.50

$-122.14$

121.78

$\checkmark 120.02$

$\sim 118.67$

$-115.88$

113.39
-113.07 
${ }^{1} \mathrm{H}$ NMR (400 MHz, $\mathrm{CDCl}_{3}$ ) spectrum of $\mathbf{4 g}$

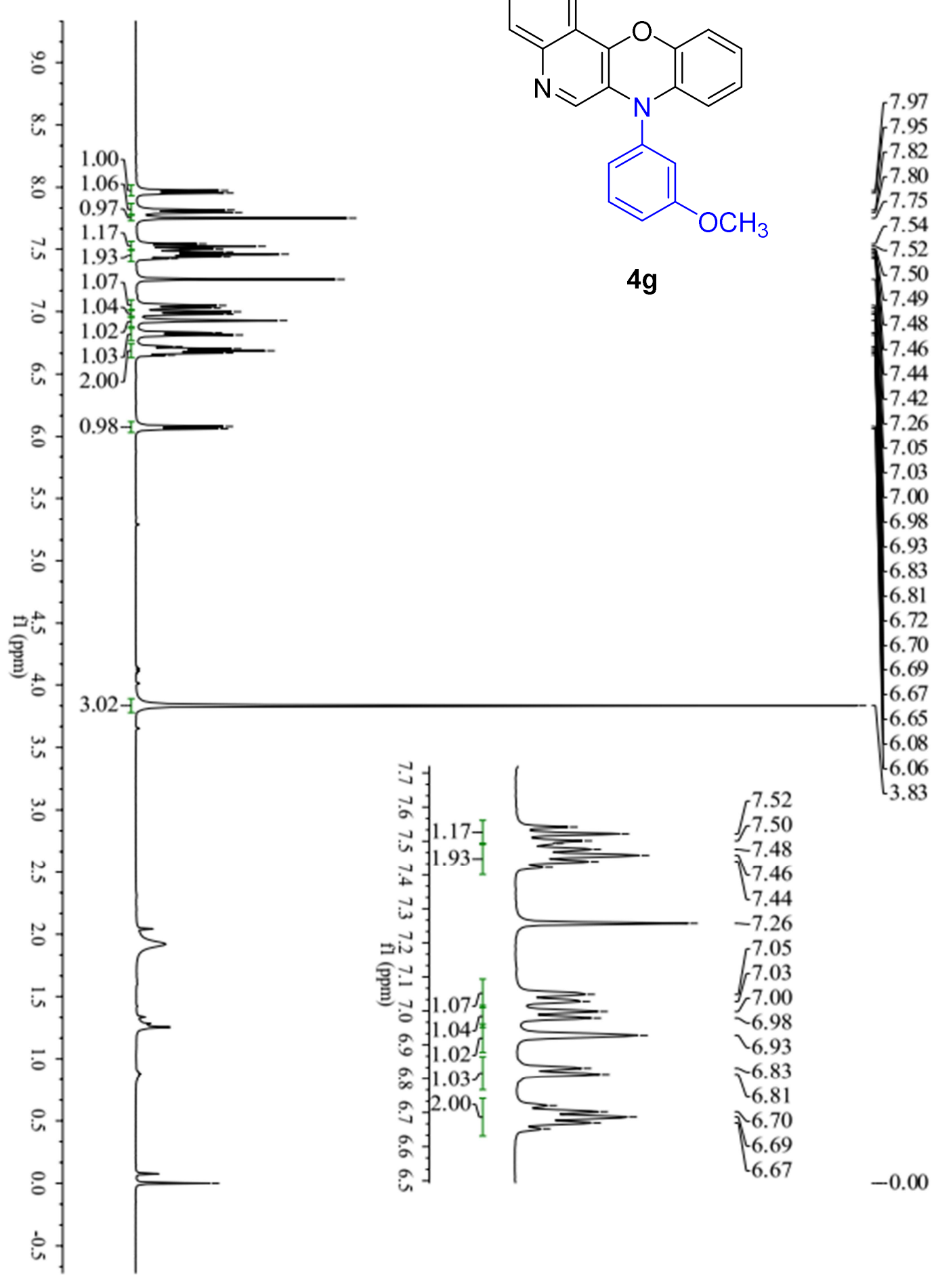




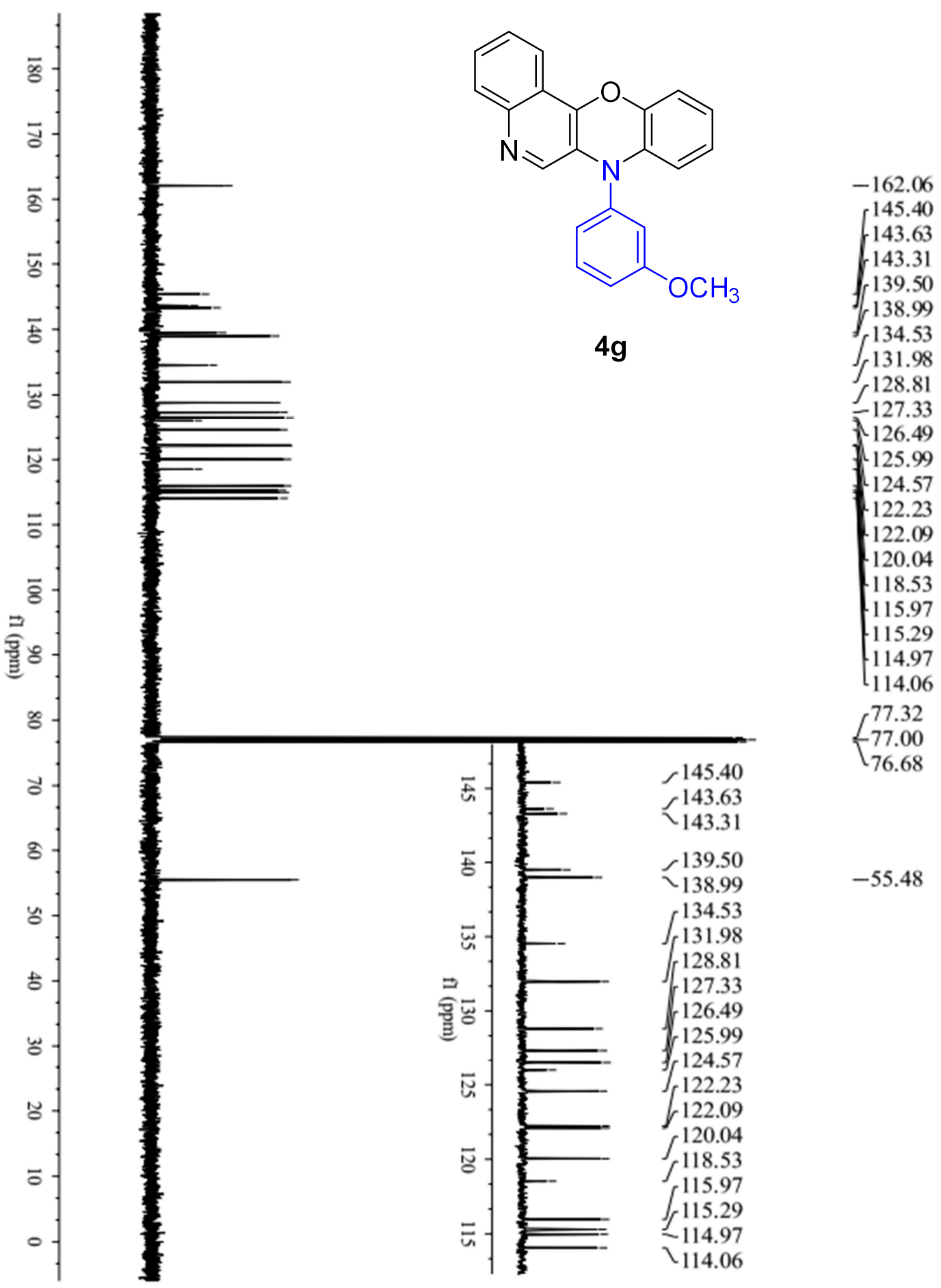


${ }^{1} \mathrm{H}$ NMR $\left(600 \mathrm{MHz}, \mathrm{CDCl}_{3}\right)$ spectrum of $\mathbf{4 h}$

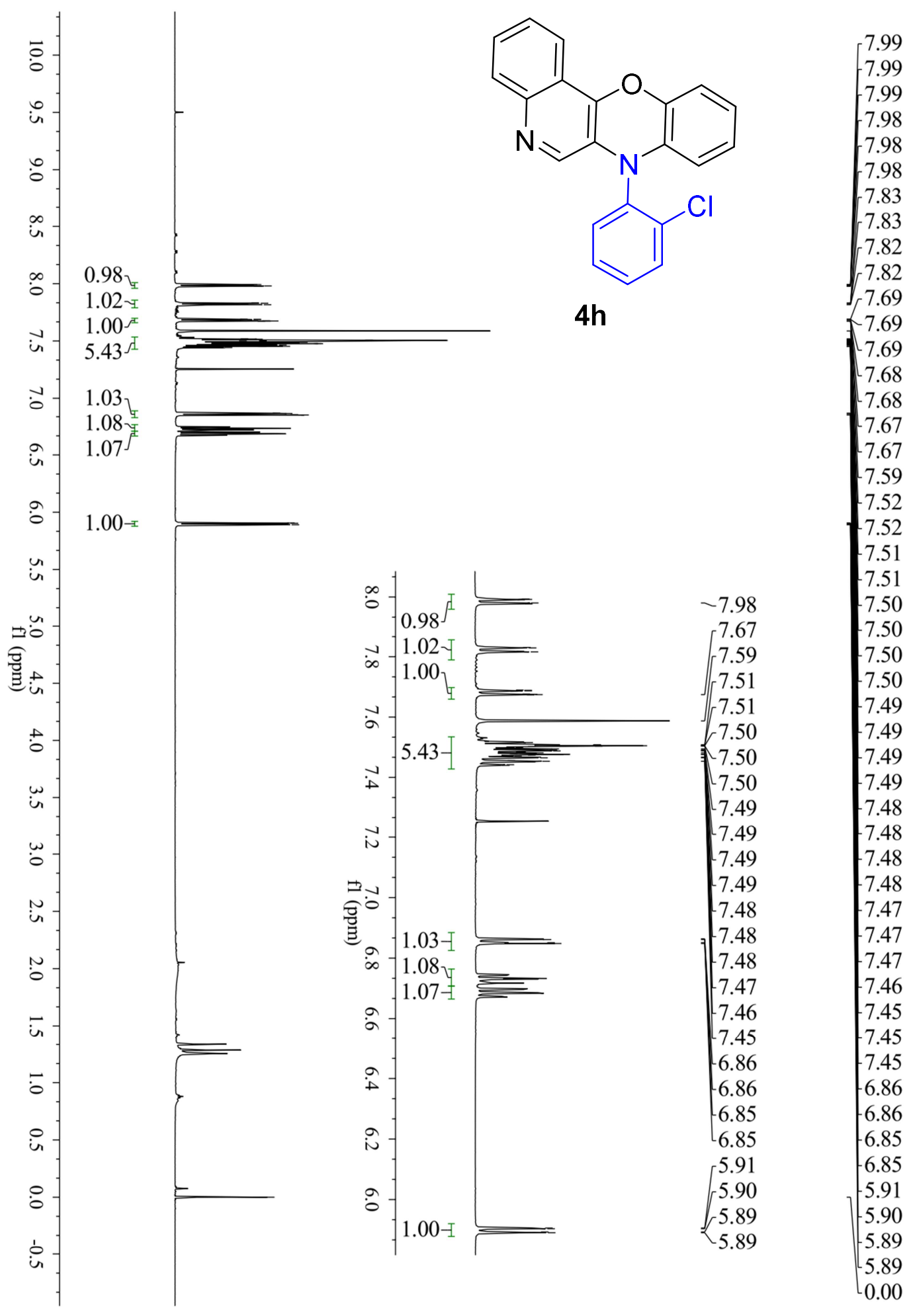



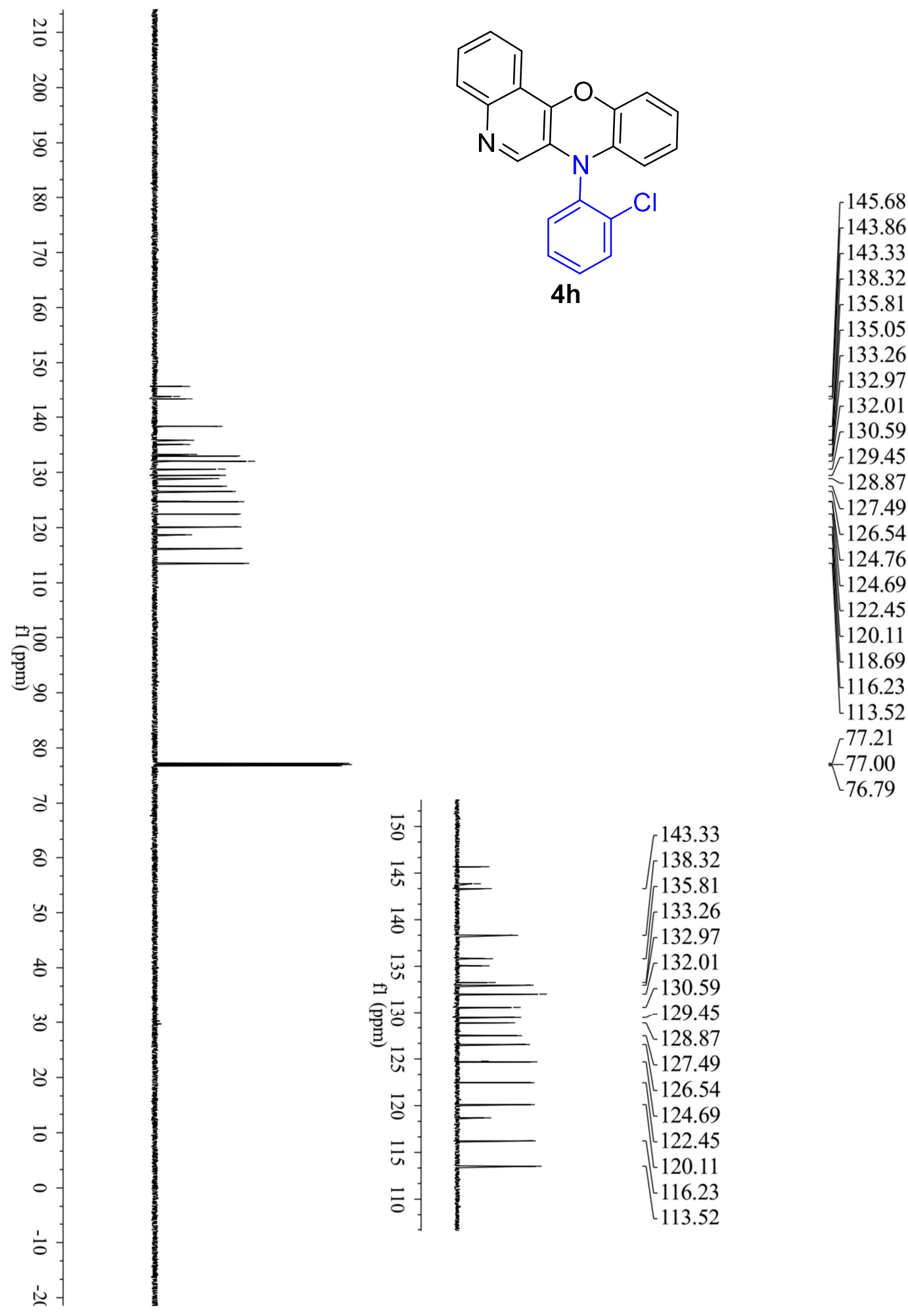

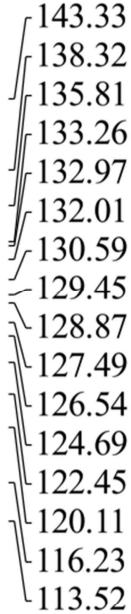


${ }^{1} \mathrm{H}$ NMR (400 MHz, $\mathrm{CDCl}_{3}$ ) spectrum of $\mathbf{4 i}$
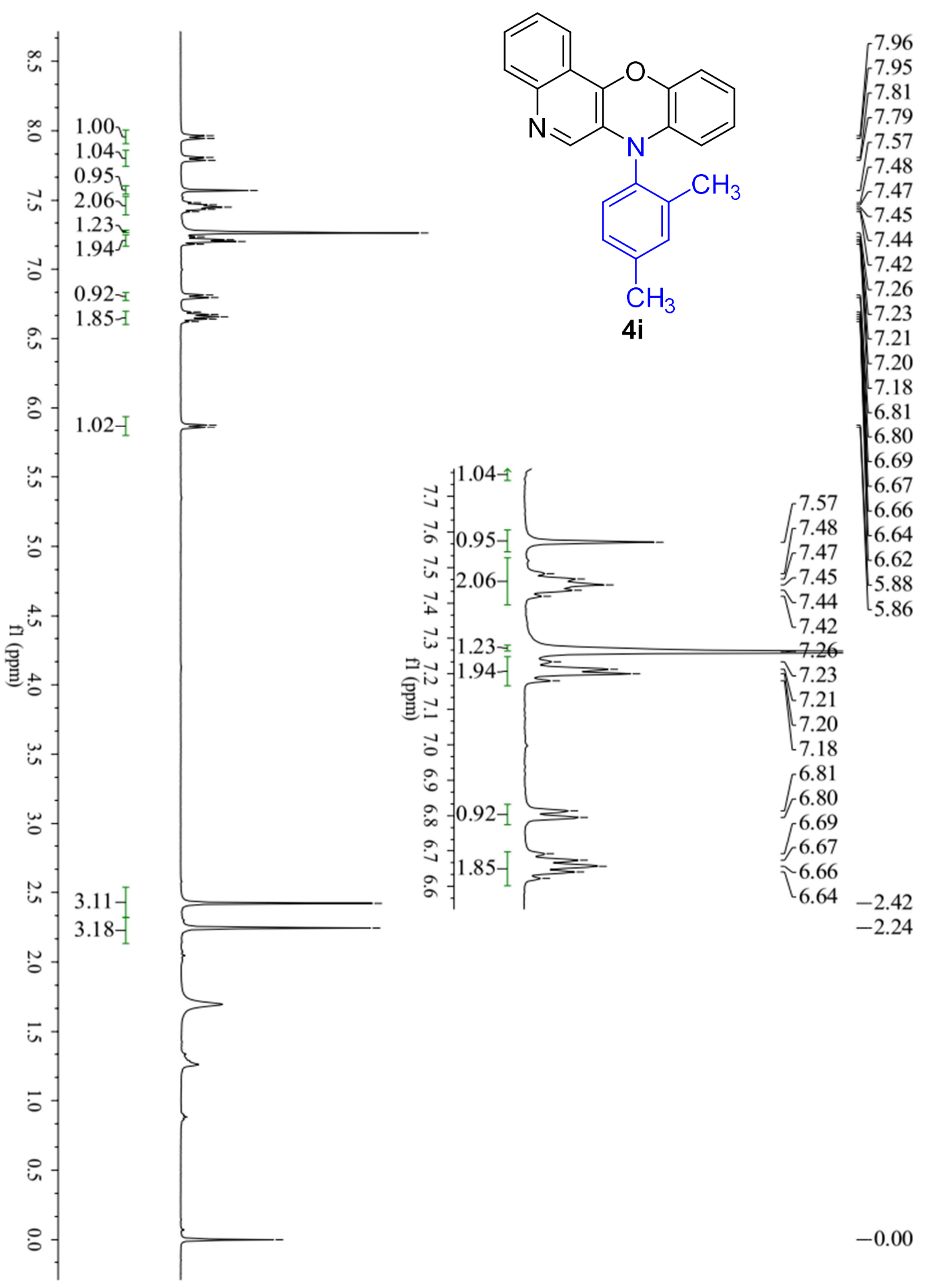
${ }^{13} \mathrm{C}\left\{{ }^{1} \mathrm{H}\right\}$ NMR $\left(101 \mathrm{MHz}, \mathrm{CDCl}_{3}\right)$ spectrum of $\mathbf{4 i}$

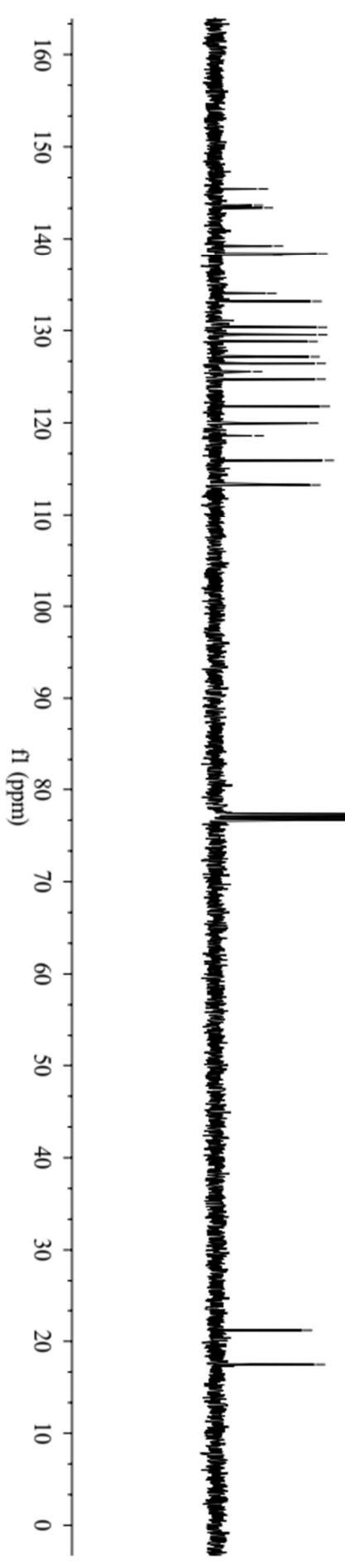<smiles>[CH]c1ccc(N2c3ccccc3Oc3c2cnc2ccccc32)c(C)c1</smiles>

145.43

143.65

143.39 139.24

138.38

138.22

134.04

133.21

133.17

130.36

$-129.54$

128.82

127.16

126.43

125.55

124.72

121.78

$-119.96$

118.59

115.92

113.26

77.32

$-77.00$

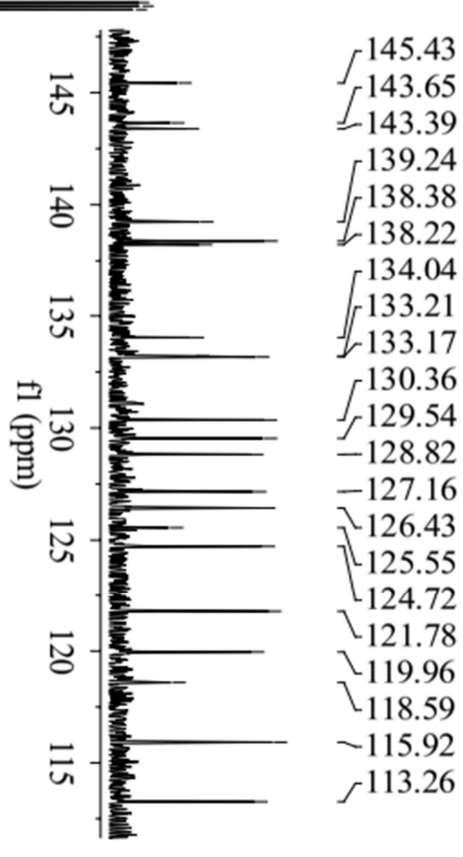

$-21.20$

$-17.48$ 
${ }^{1} \mathrm{H}$ NMR (400 MHz, $\left.\mathrm{CDCl}_{3}\right)$ spectrum of $\mathbf{4} \mathbf{j}$

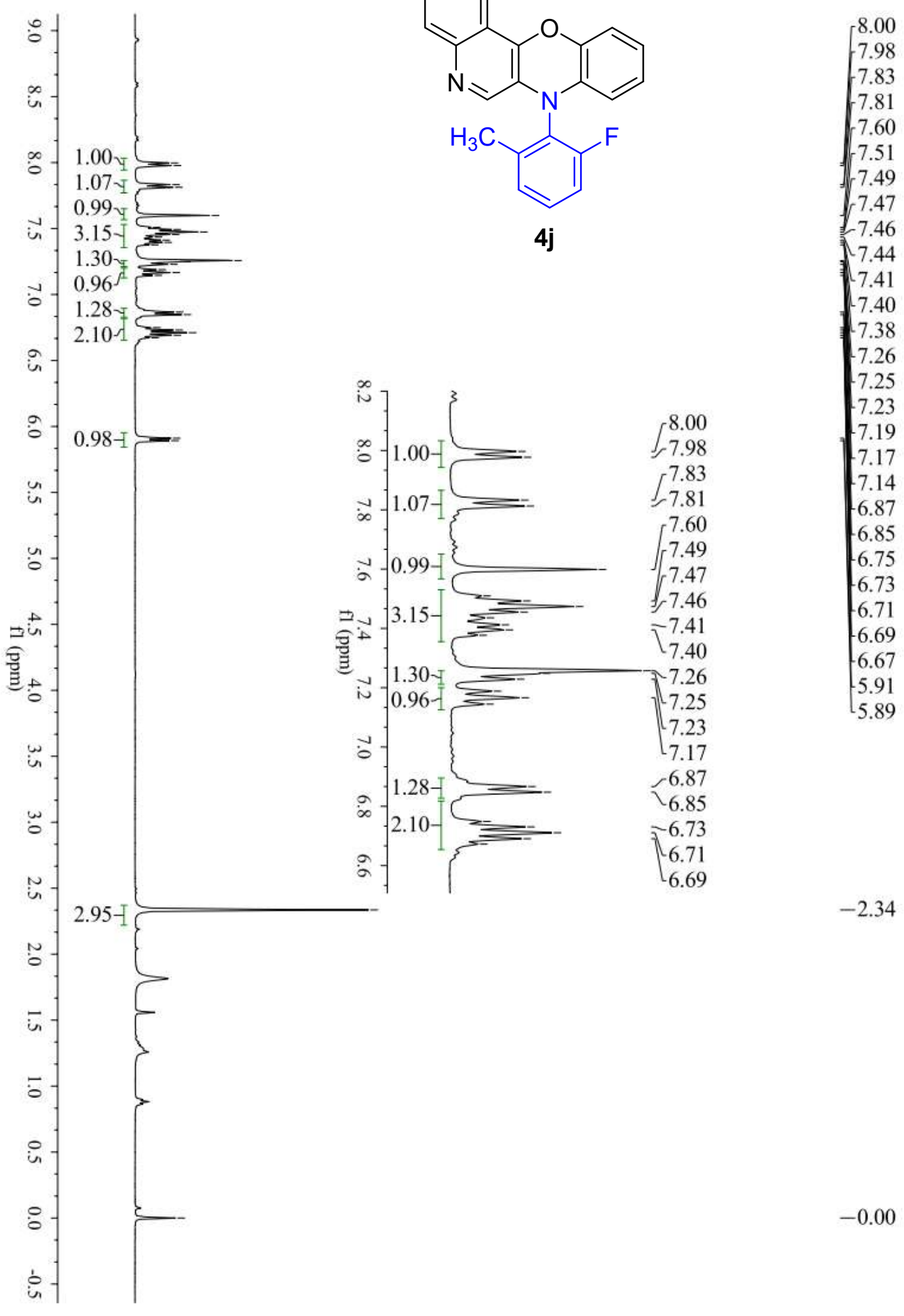


${ }^{13} \mathrm{C}\left\{{ }^{1} \mathrm{H}\right\}$ NMR $\left(101 \mathrm{MHz}, \mathrm{CDCl}_{3}\right)$ spectrum of $\mathbf{4 j}$

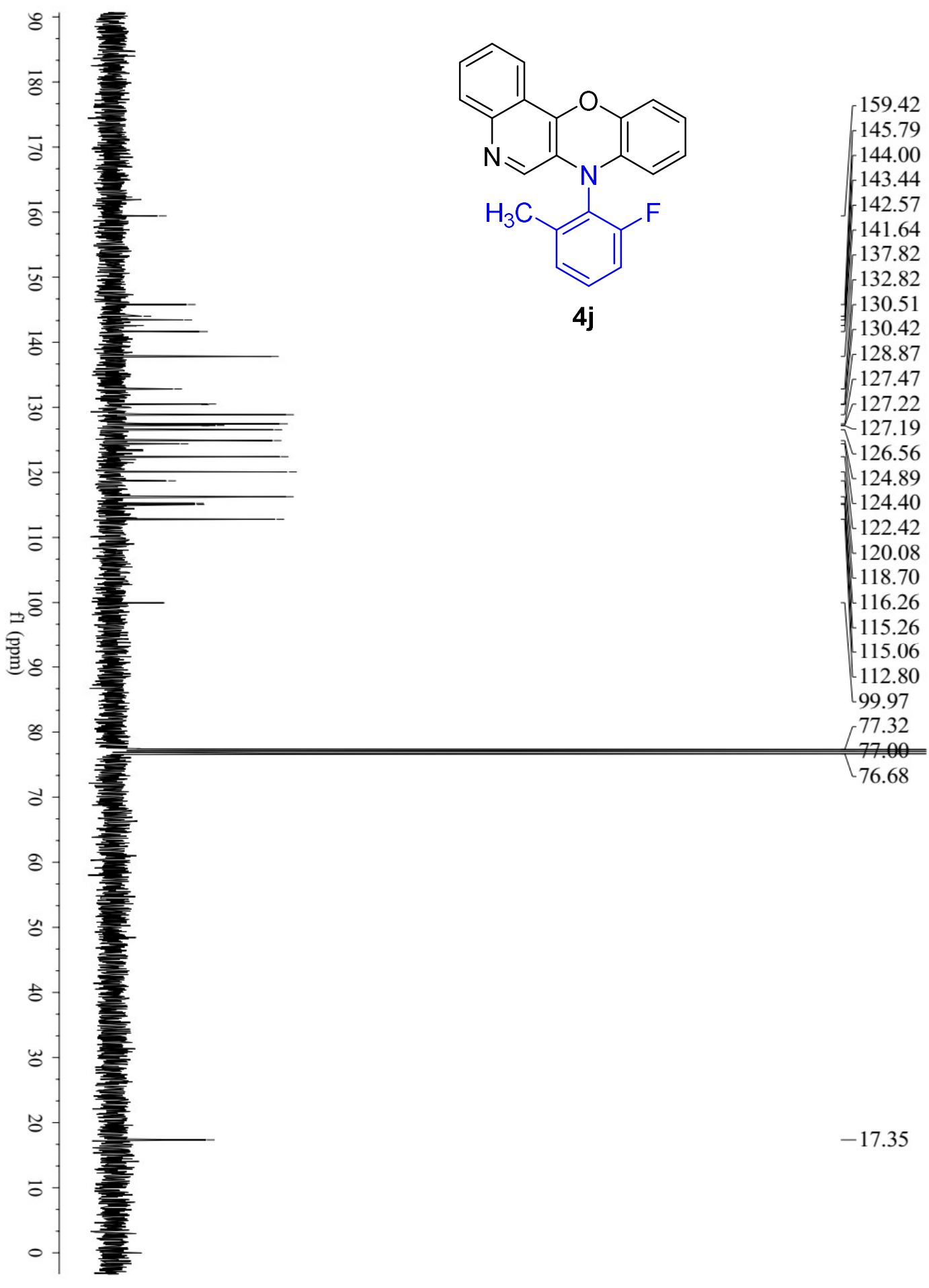


${ }^{19} \mathrm{~F}$ NMR $\left(376 \mathrm{MHz}, \mathrm{CDCl}_{3}\right)$ spectrum of $\mathbf{4 j}$

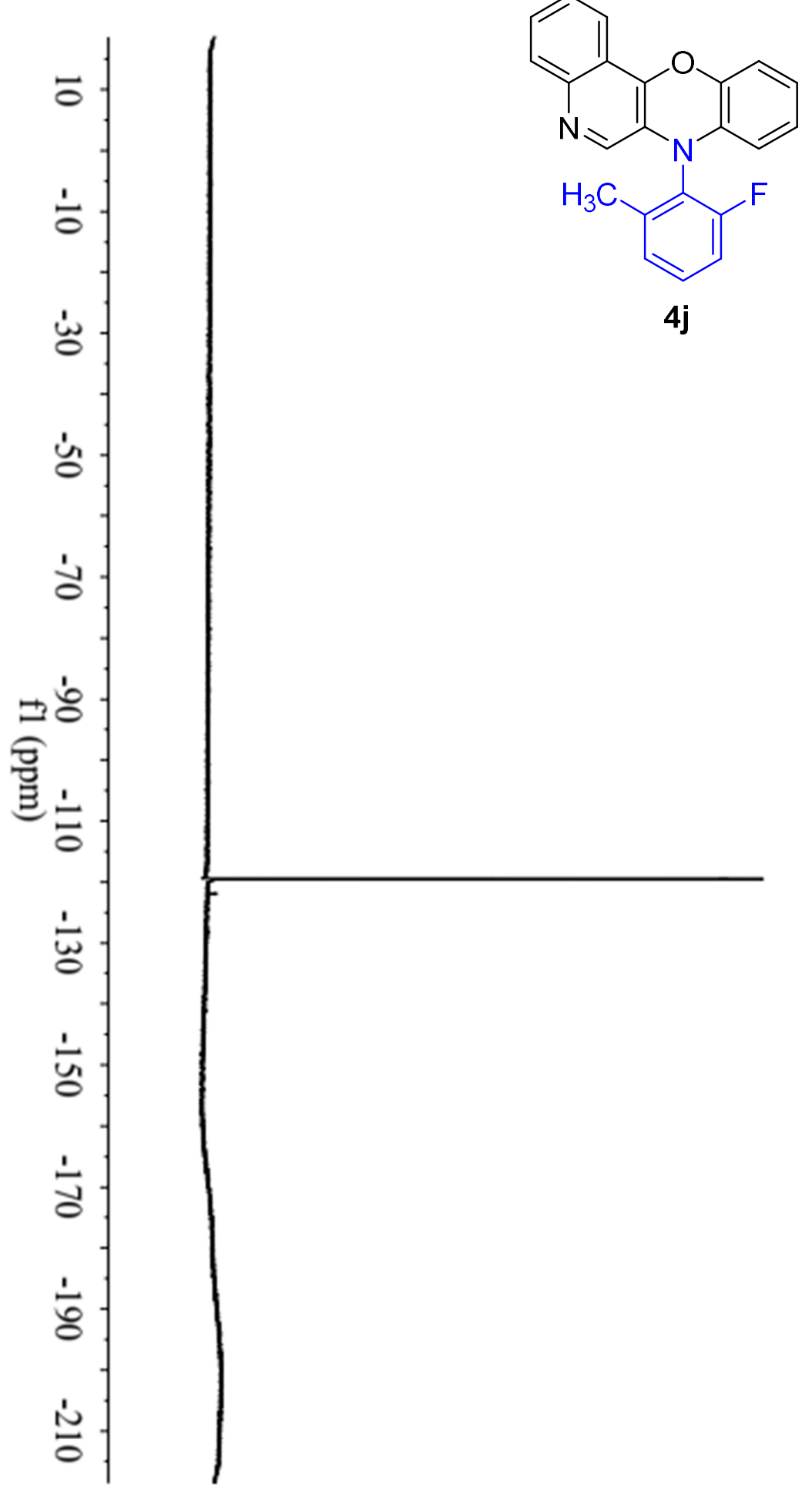


${ }^{1} \mathrm{H}$ NMR (400 MHz, $\mathrm{CDCl}_{3}$ ) spectrum of $\mathbf{4 k}$

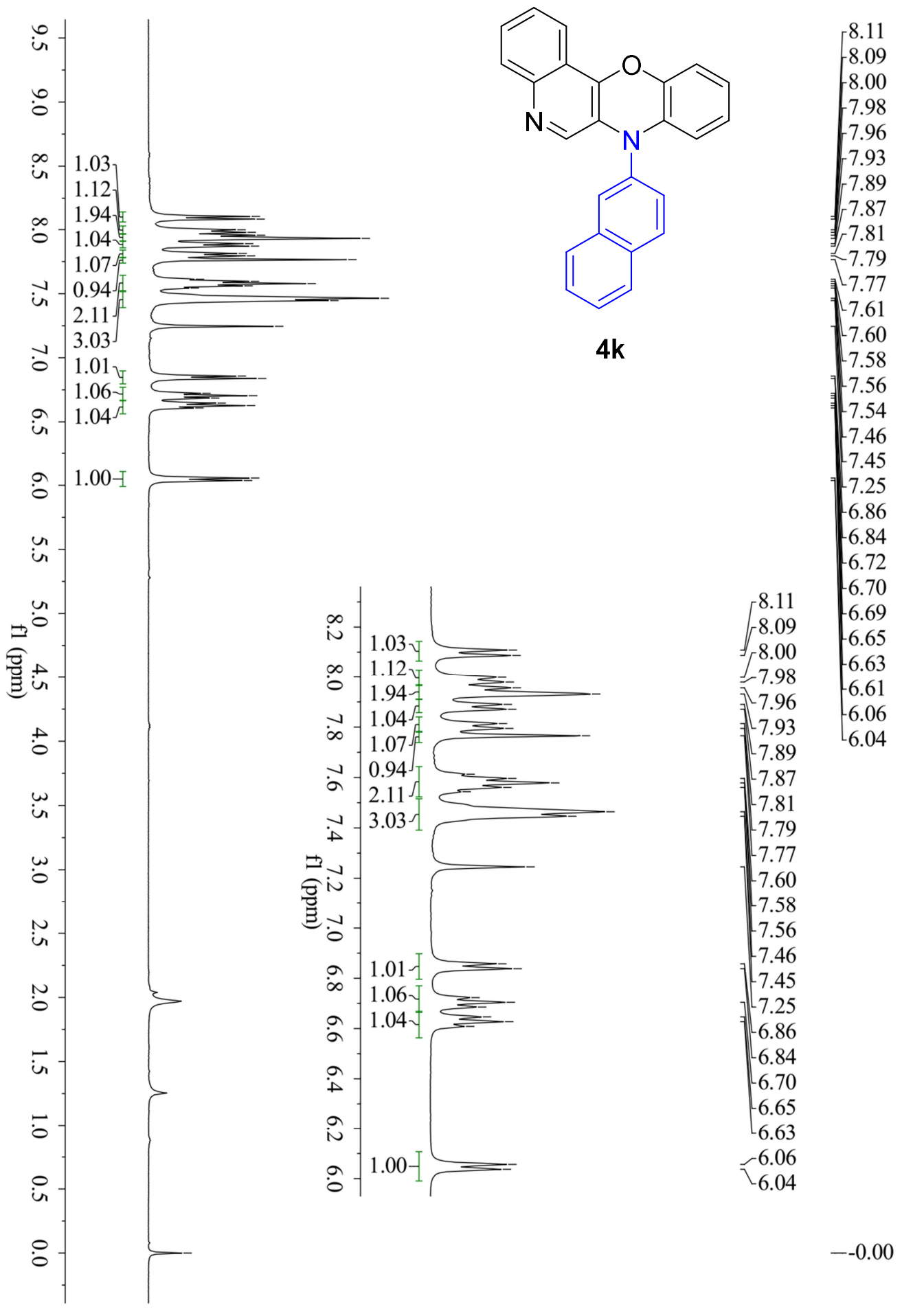




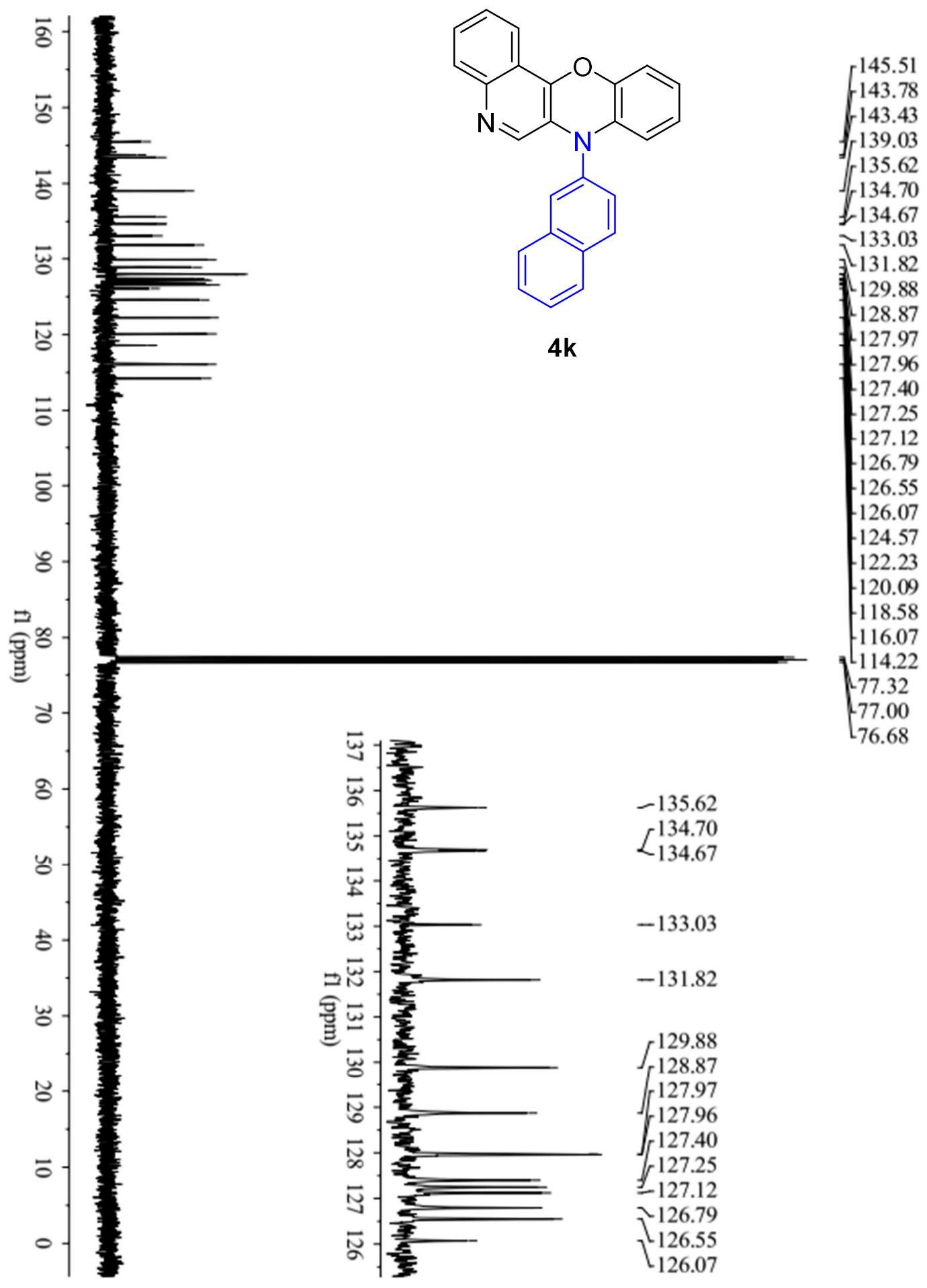


${ }^{1} \mathrm{H}$ NMR (400 MHz, $\mathrm{CDCl}_{3}$ ) spectrum of $4 \mathbf{I}$

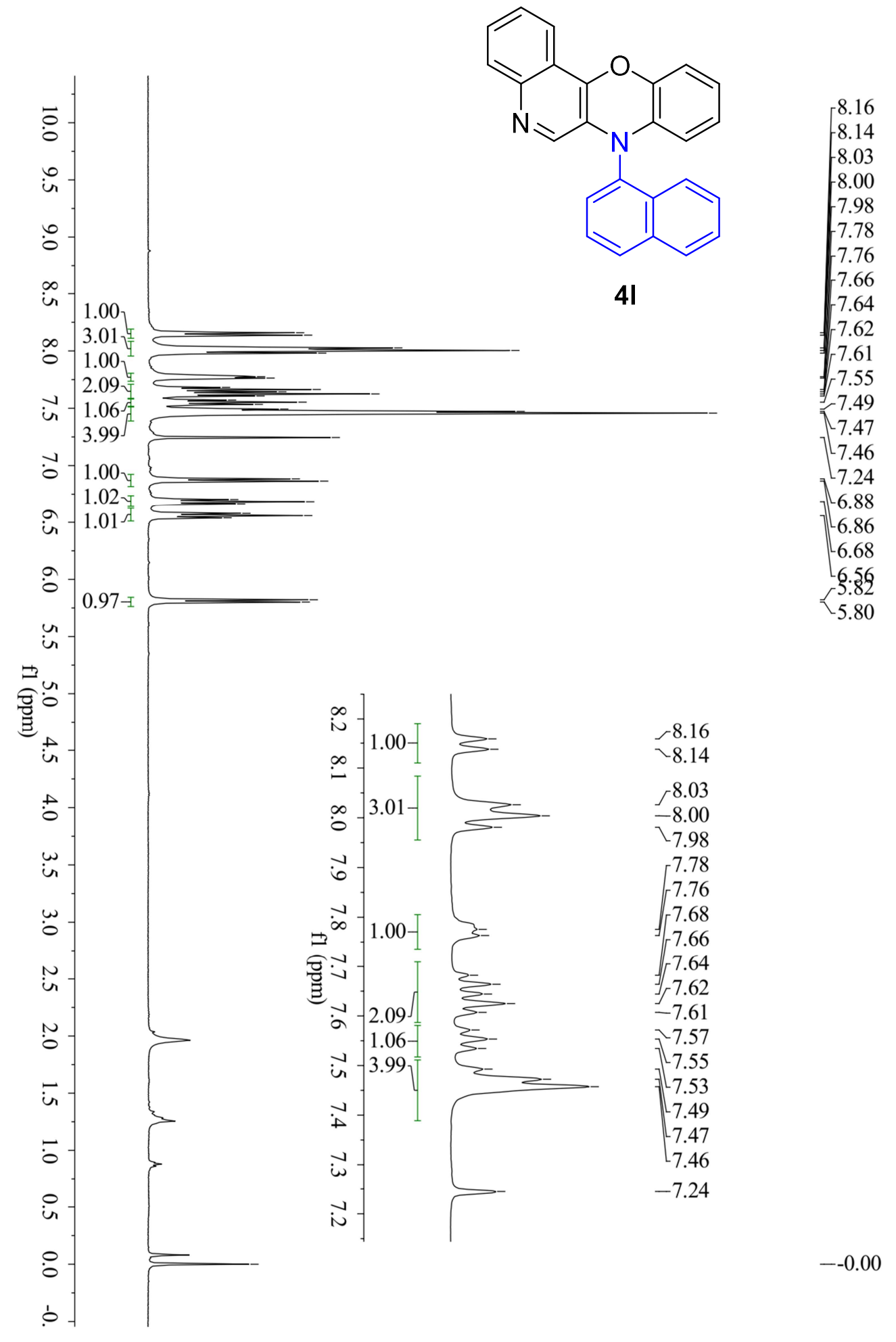


${ }^{13} \mathrm{C}\left\{{ }^{1} \mathrm{H}\right\}$ NMR $\left(101 \mathrm{MHz}, \mathrm{CDCl}_{3}\right)$ spectrum of $4 \mathbf{l}$

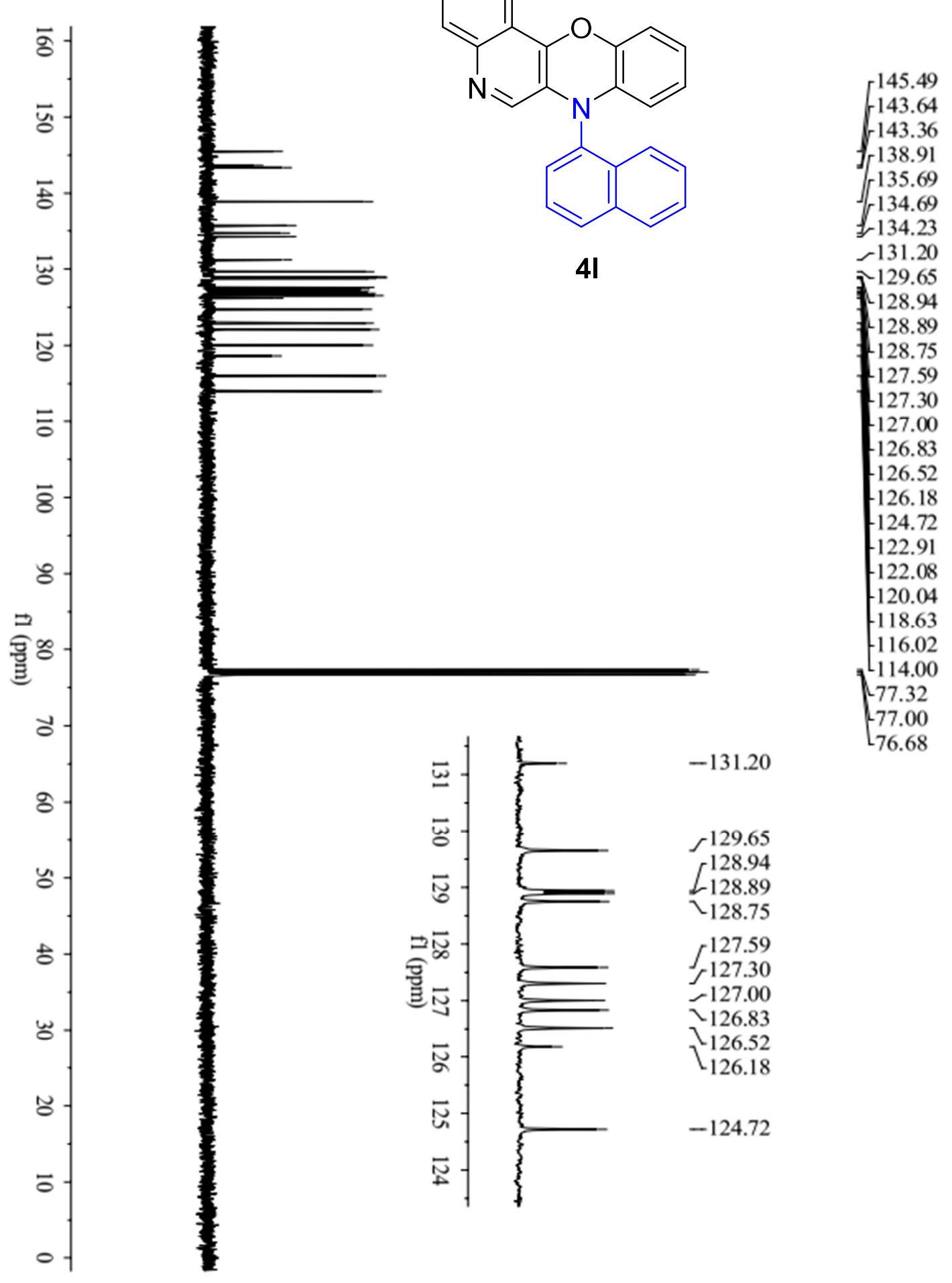




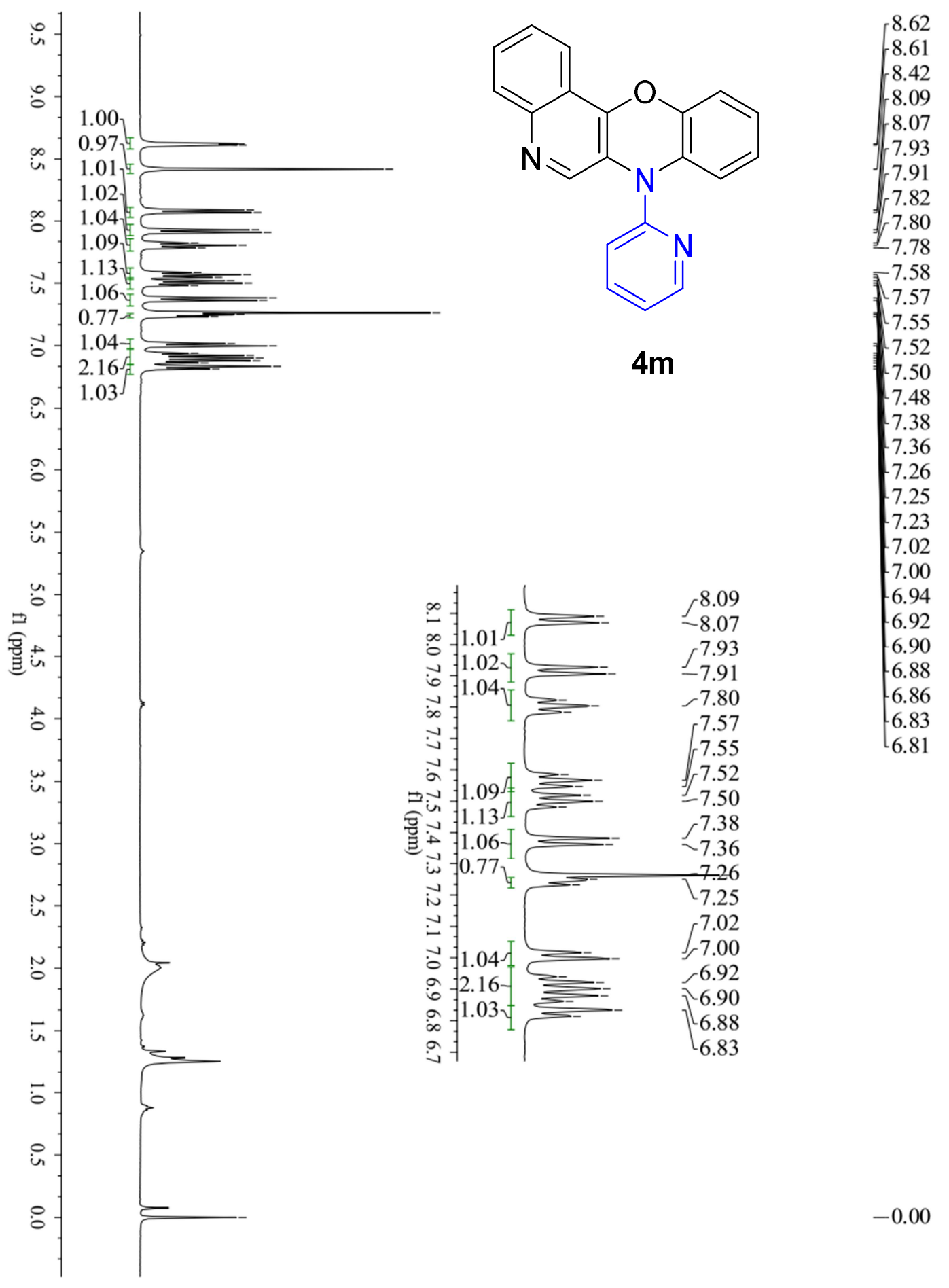




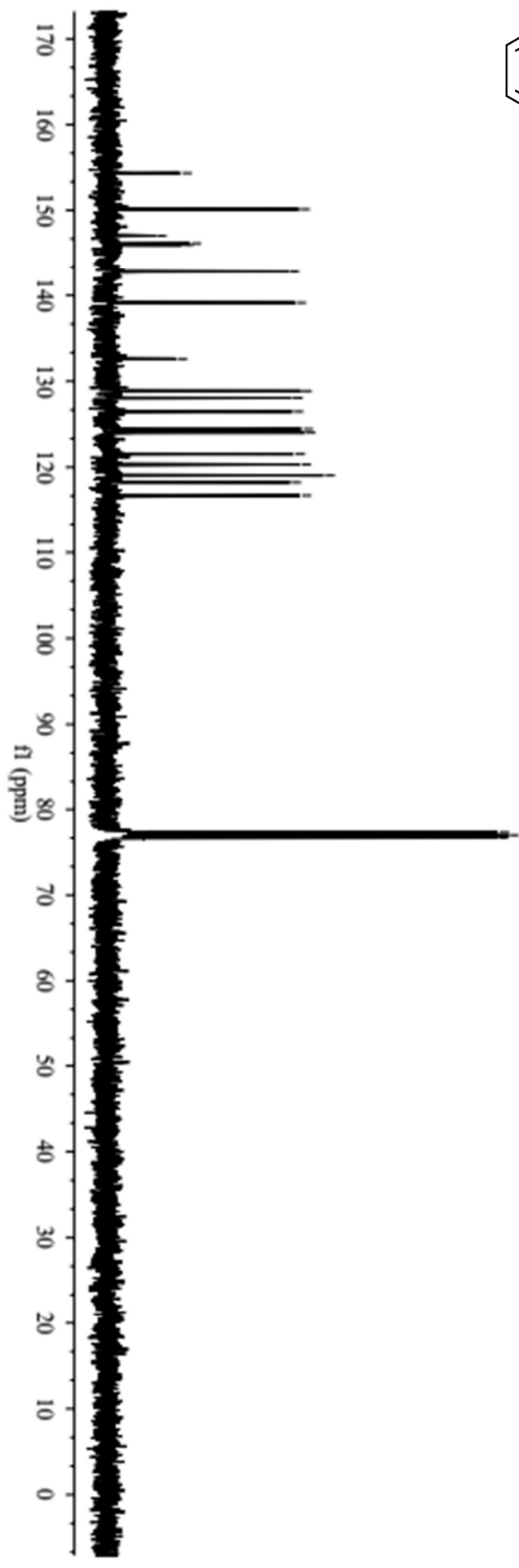<smiles>c1ccc(N2c3ccccc3Oc3c2cnc2ccccc32)nc1</smiles>

154.34

150.13

147.02

146.13

145.93

142.79

139.13

132.60

128.87

128.07

126.47

124.44

124.02

121.53

120.31

119.05

118.24

116.71

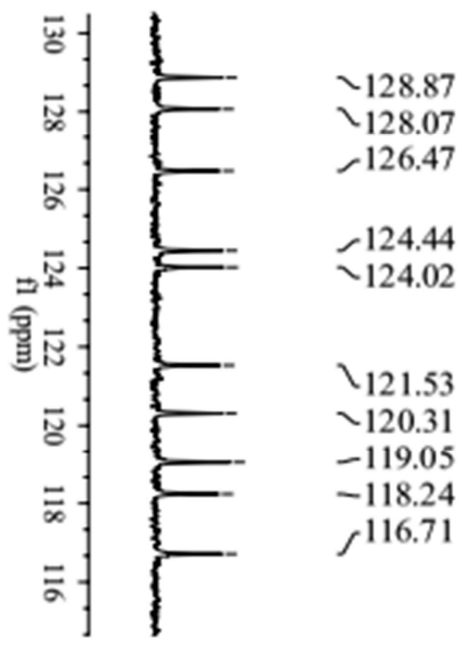


${ }^{1} \mathrm{H}$ NMR (400 MHz, $\mathrm{CDCl}_{3}$ ) spectrum of $\mathbf{4 n}$
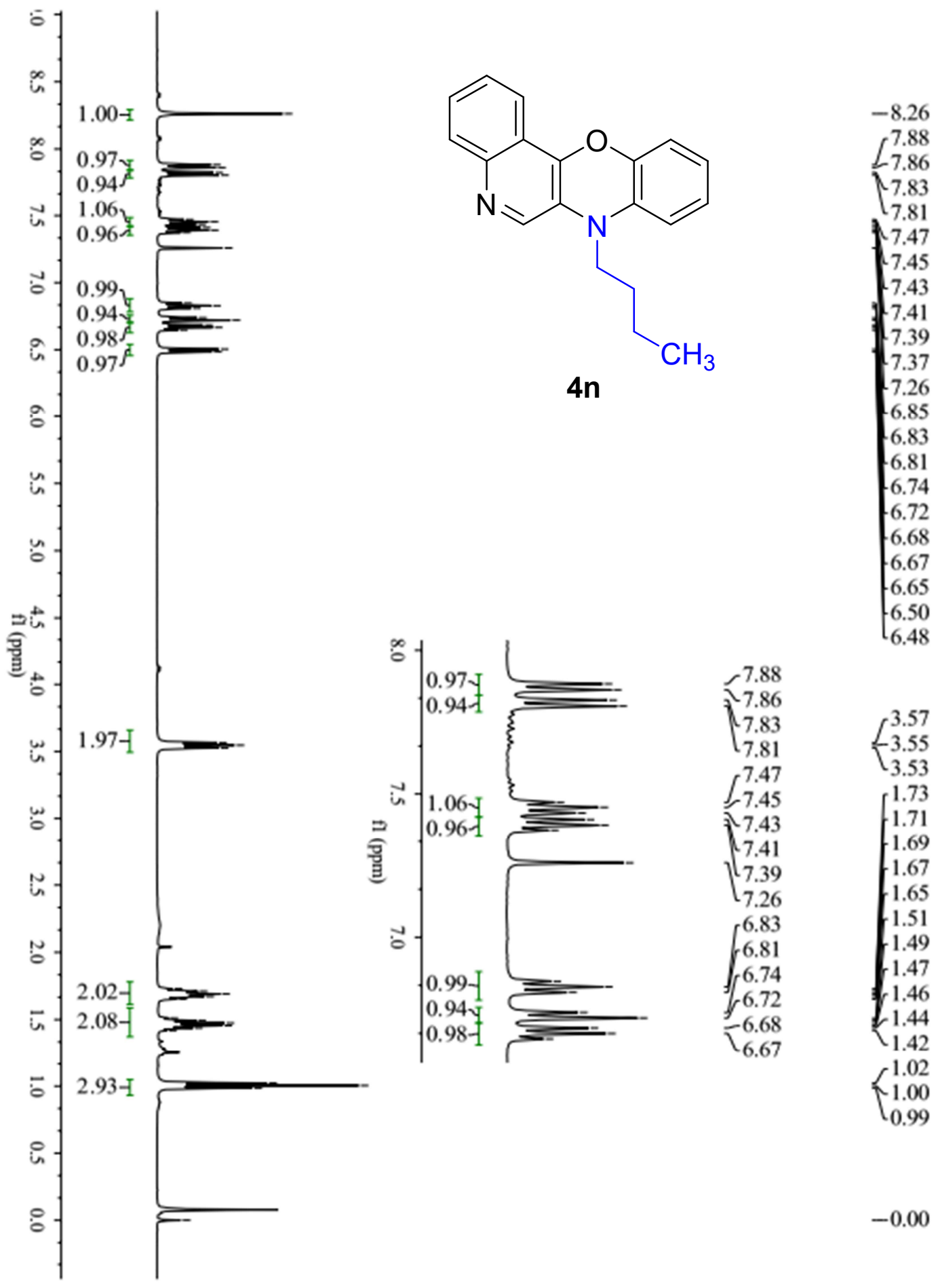
${ }^{13} \mathrm{C}\left\{{ }^{1} \mathrm{H}\right\}$ NMR $\left(101 \mathrm{MHz}, \mathrm{CDCl}_{3}\right)$ spectrum of $\mathbf{4 n}$

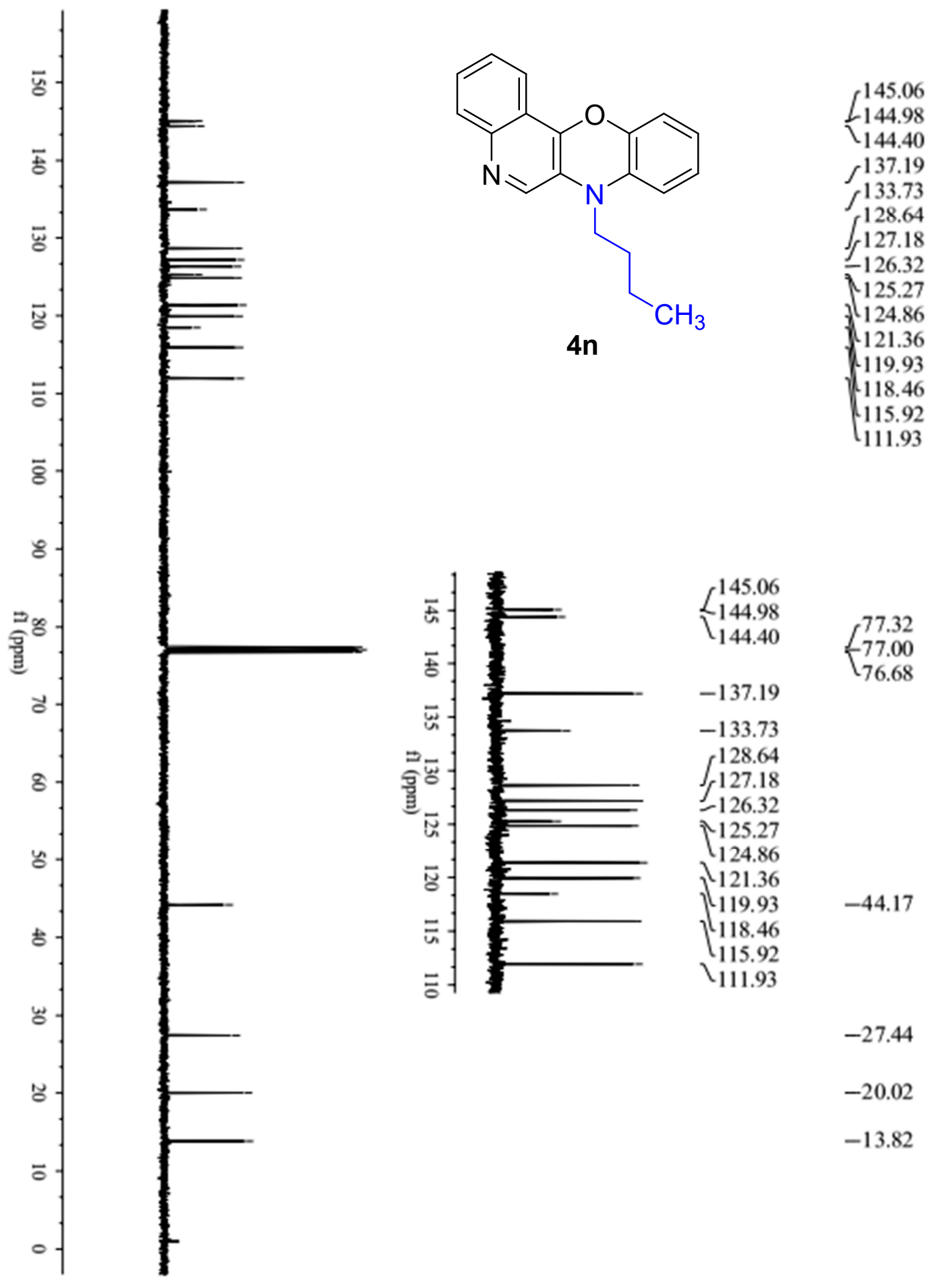


${ }^{1} \mathrm{H}$ NMR (400 MHz, $\mathrm{CDCl}_{3}$ ) spectrum of $4 \mathbf{o}$

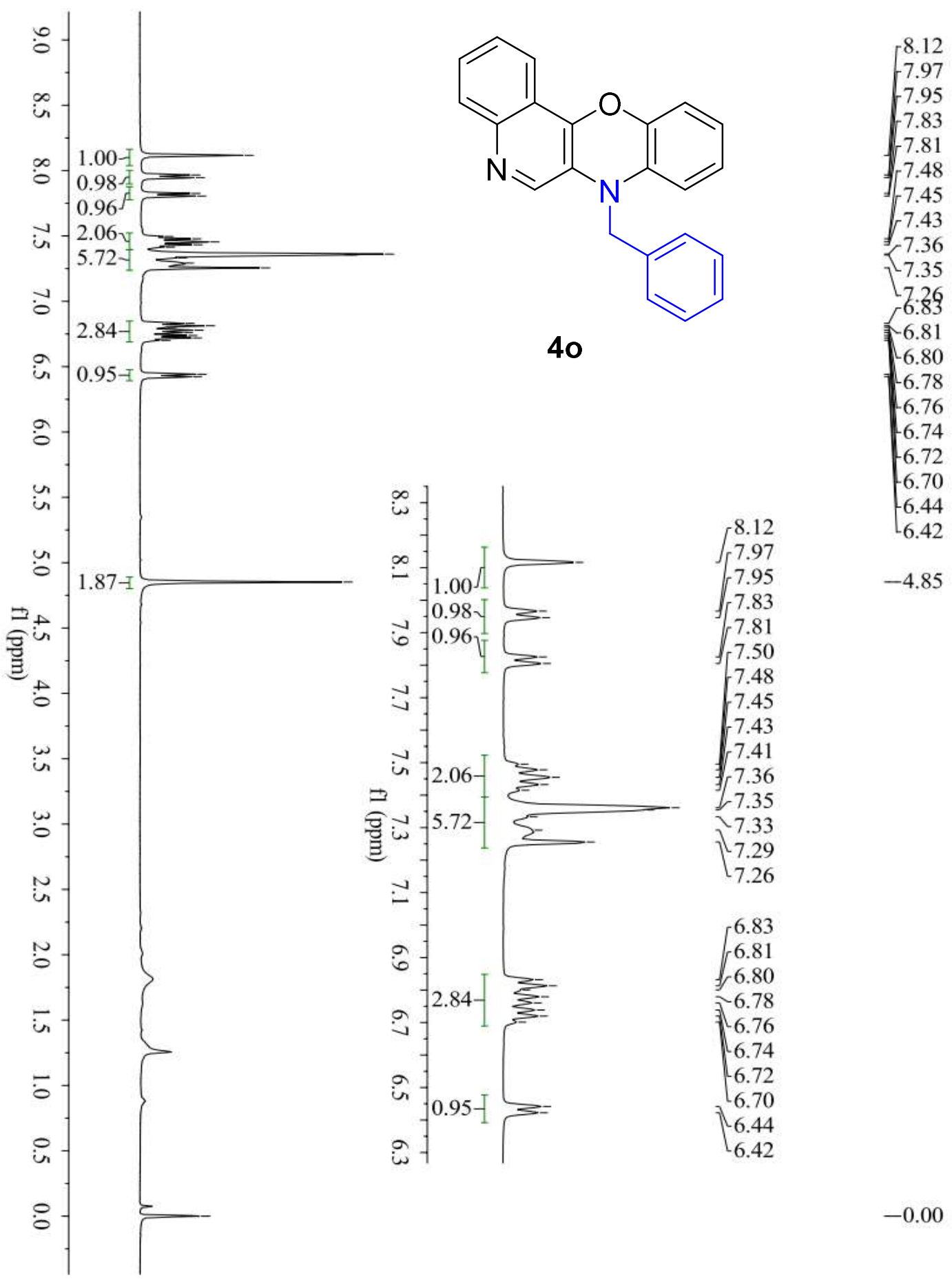


${ }^{13} \mathrm{C}\left\{{ }^{1} \mathrm{H}\right\}$ NMR $\left(101 \mathrm{MHz}, \mathrm{CDCl}_{3}\right)$ spectrum of $4 \mathbf{o}$

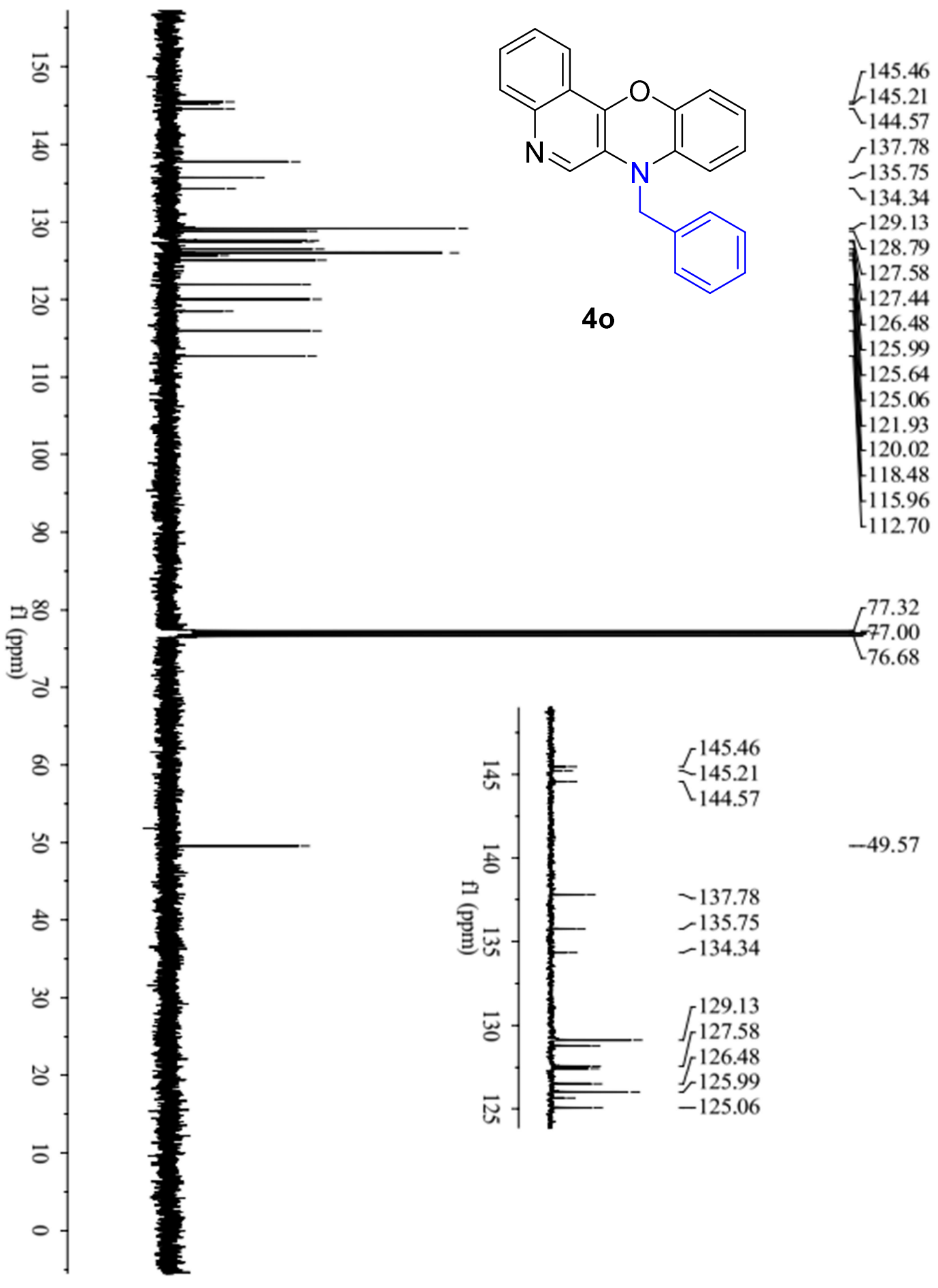


${ }^{1} \mathrm{H}$ NMR (400 MHz, $\mathrm{CDCl}_{3}$ ) spectrum of $\mathbf{4 p}$

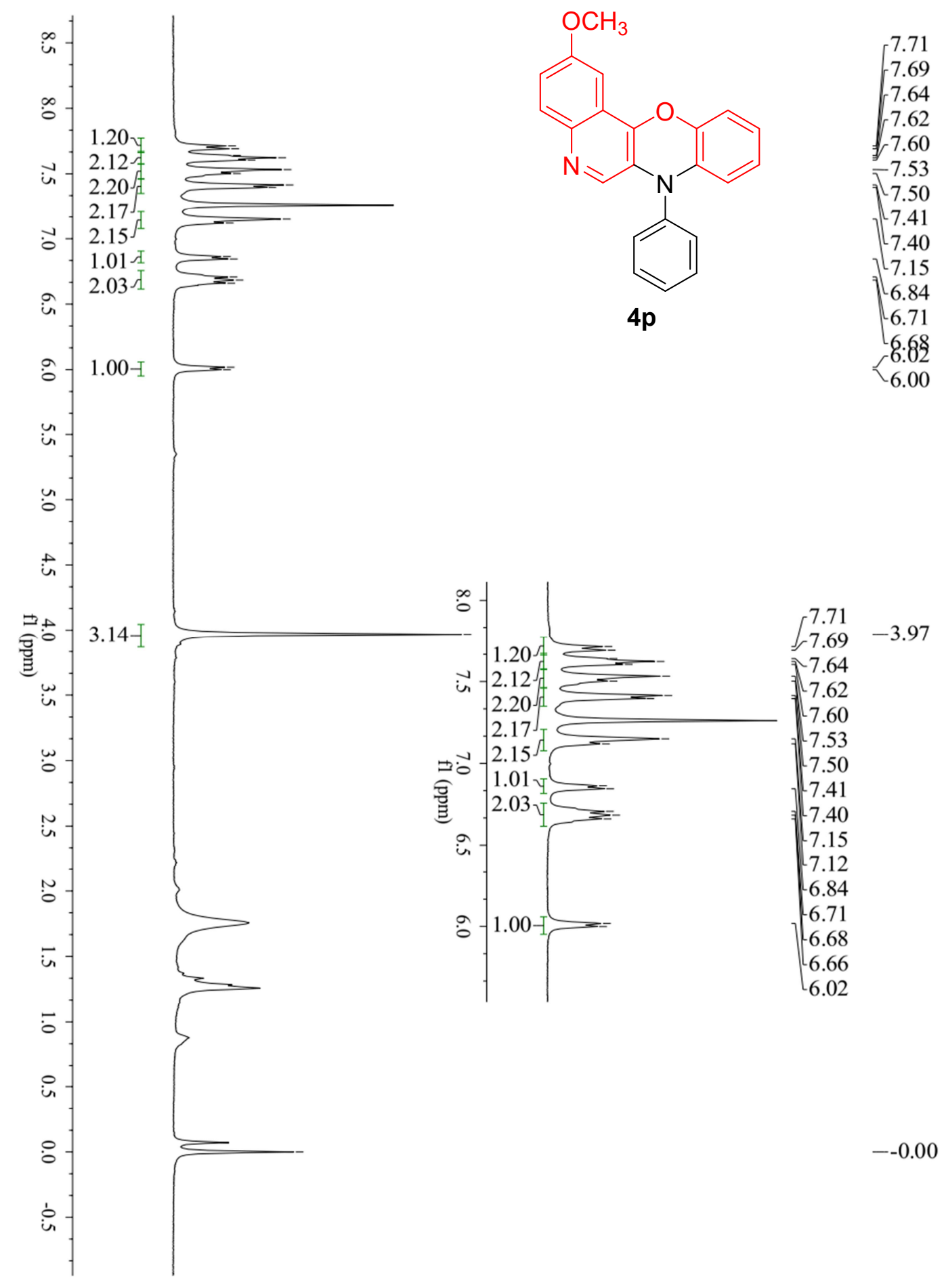




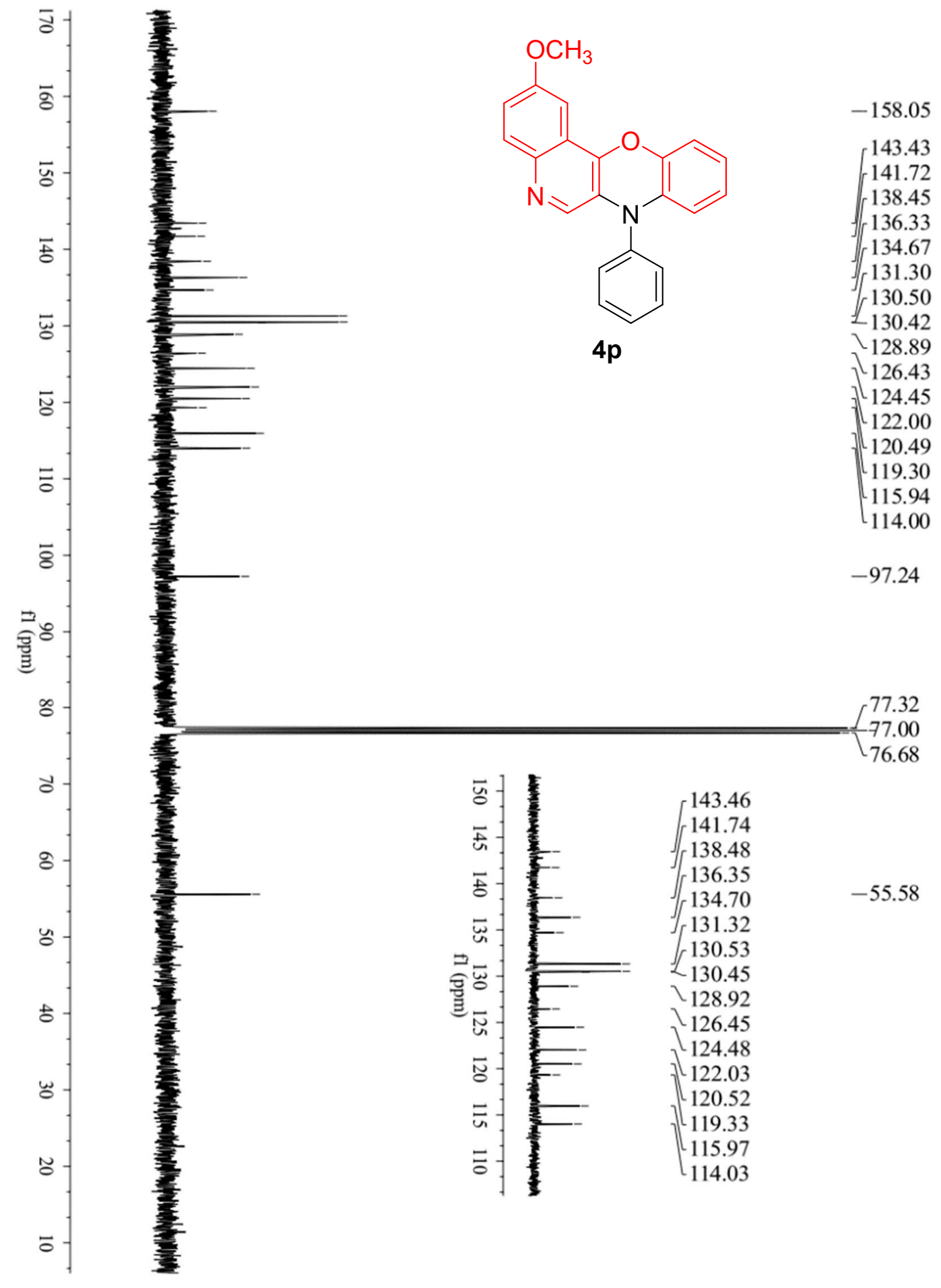


${ }^{1} \mathrm{H}$ NMR (400 MHz, $\mathrm{CDCl}_{3}$ ) spectrum of $\mathbf{4 q}$
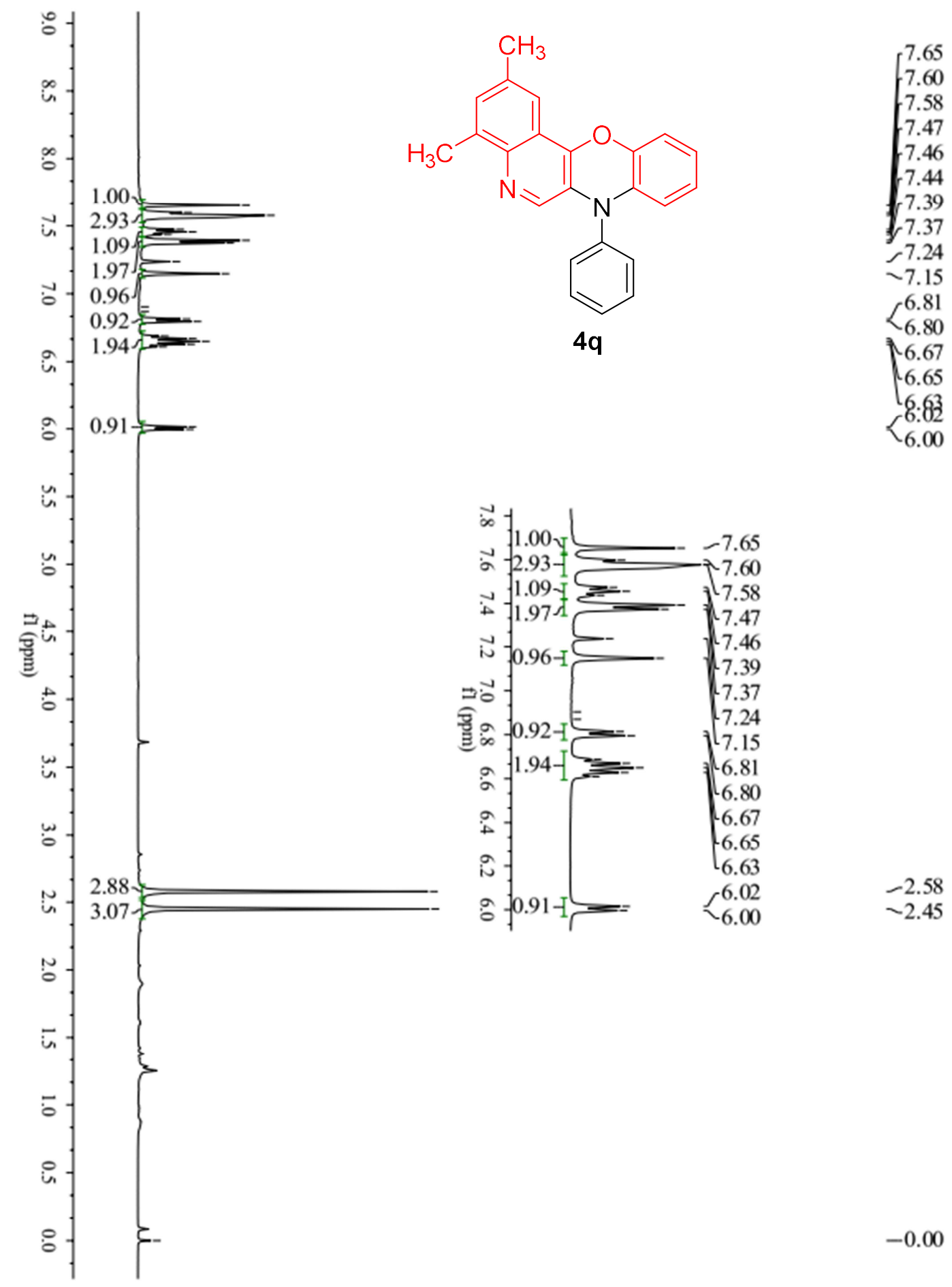

$-0.00$ 


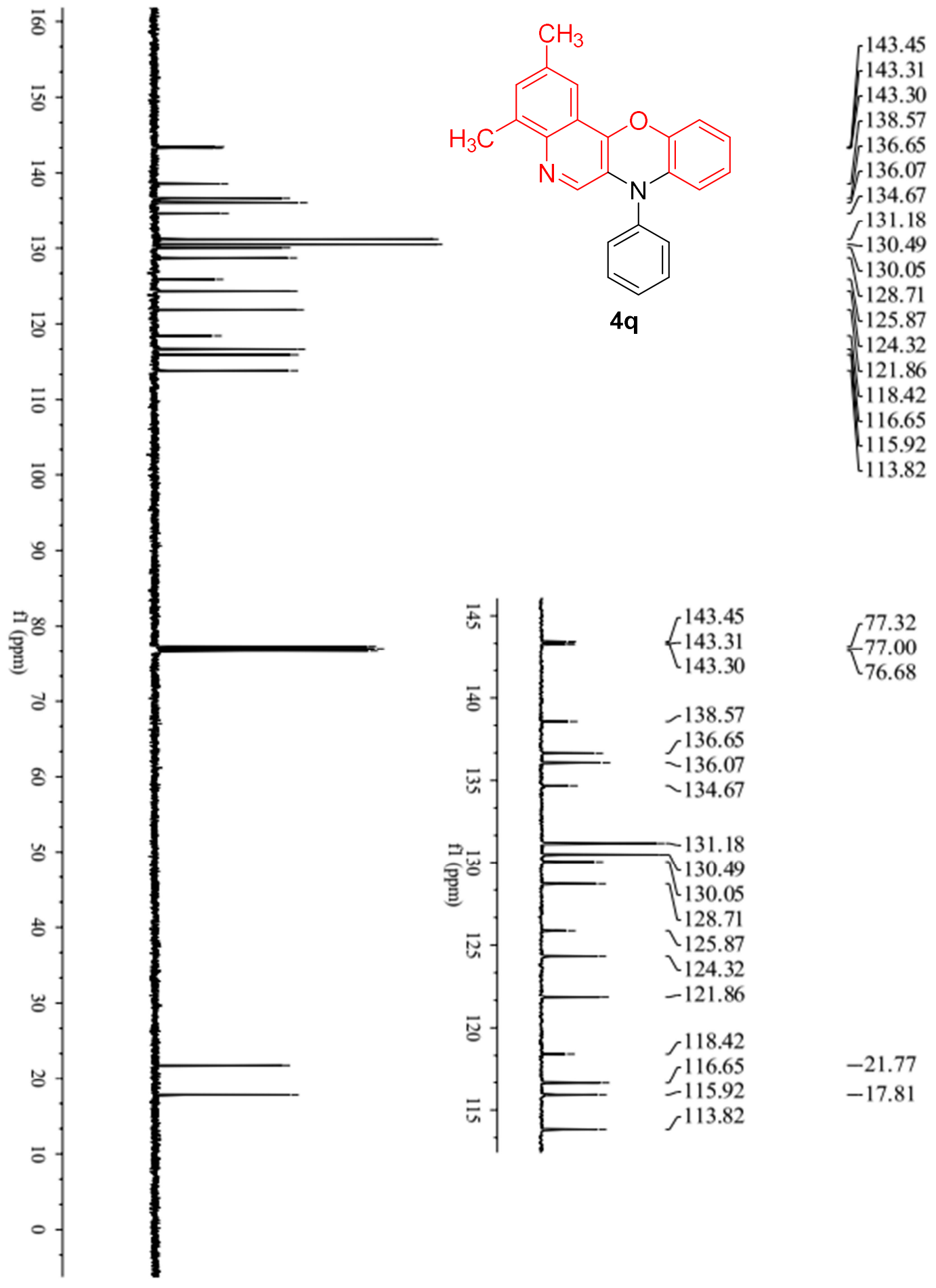


${ }^{1} \mathrm{H}$ NMR (400 MHz, $\mathrm{CDCl}_{3}$ ) spectrum of $\mathbf{4 r}$

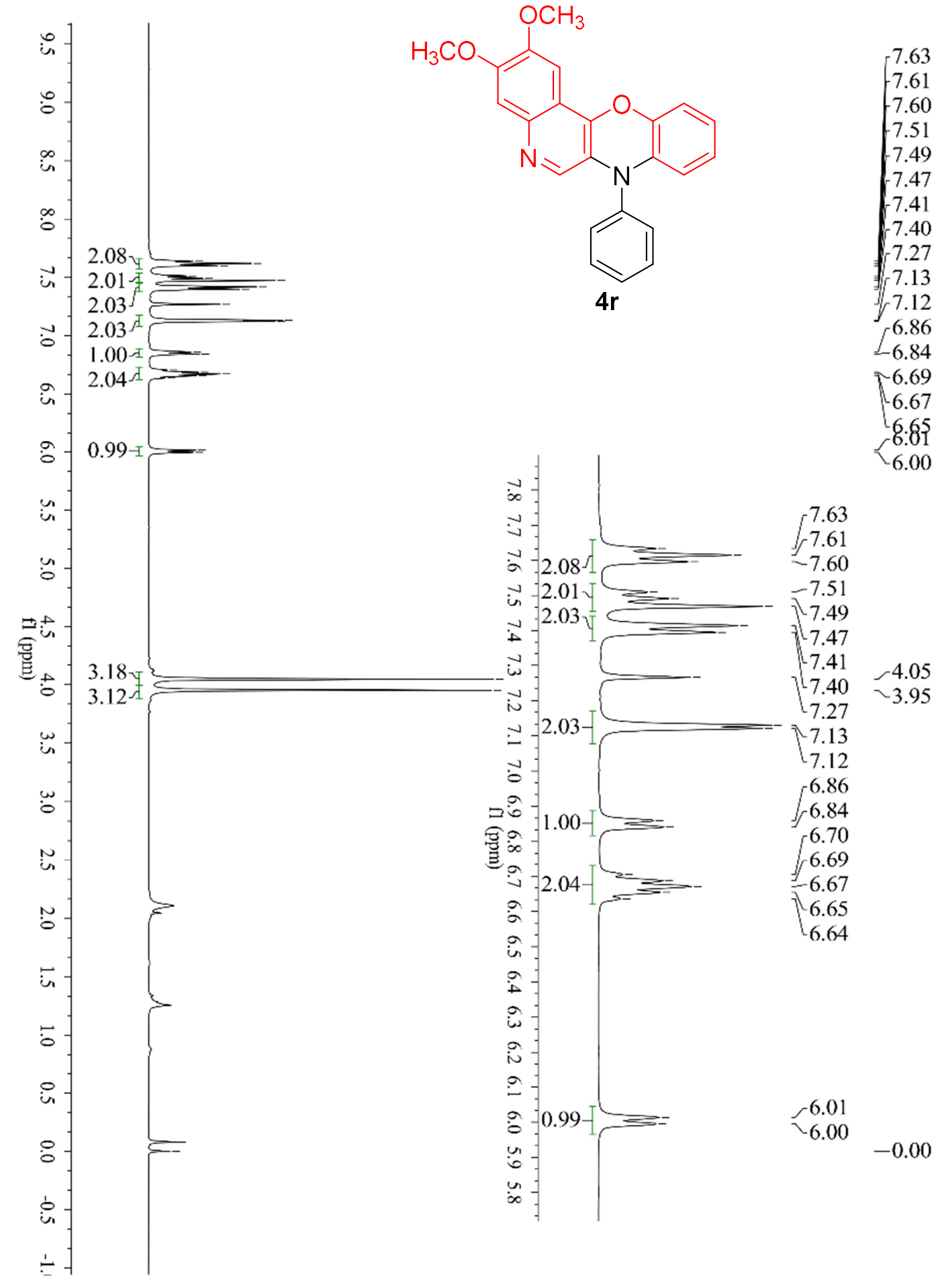




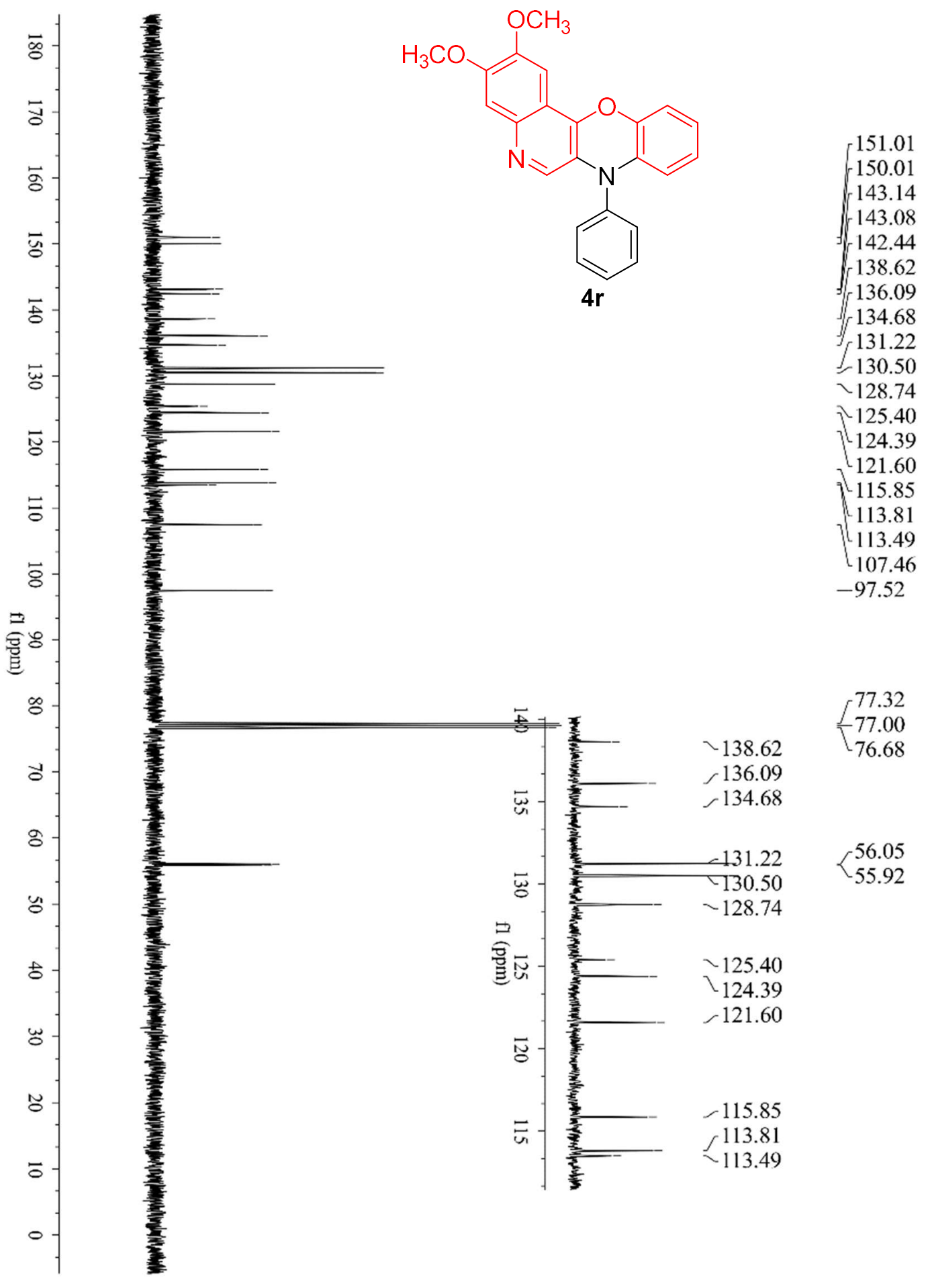


${ }^{1} \mathrm{H}$ NMR (400 MHz, $\mathrm{CDCl}_{3}$ ) spectrum of $\mathbf{4 s}$

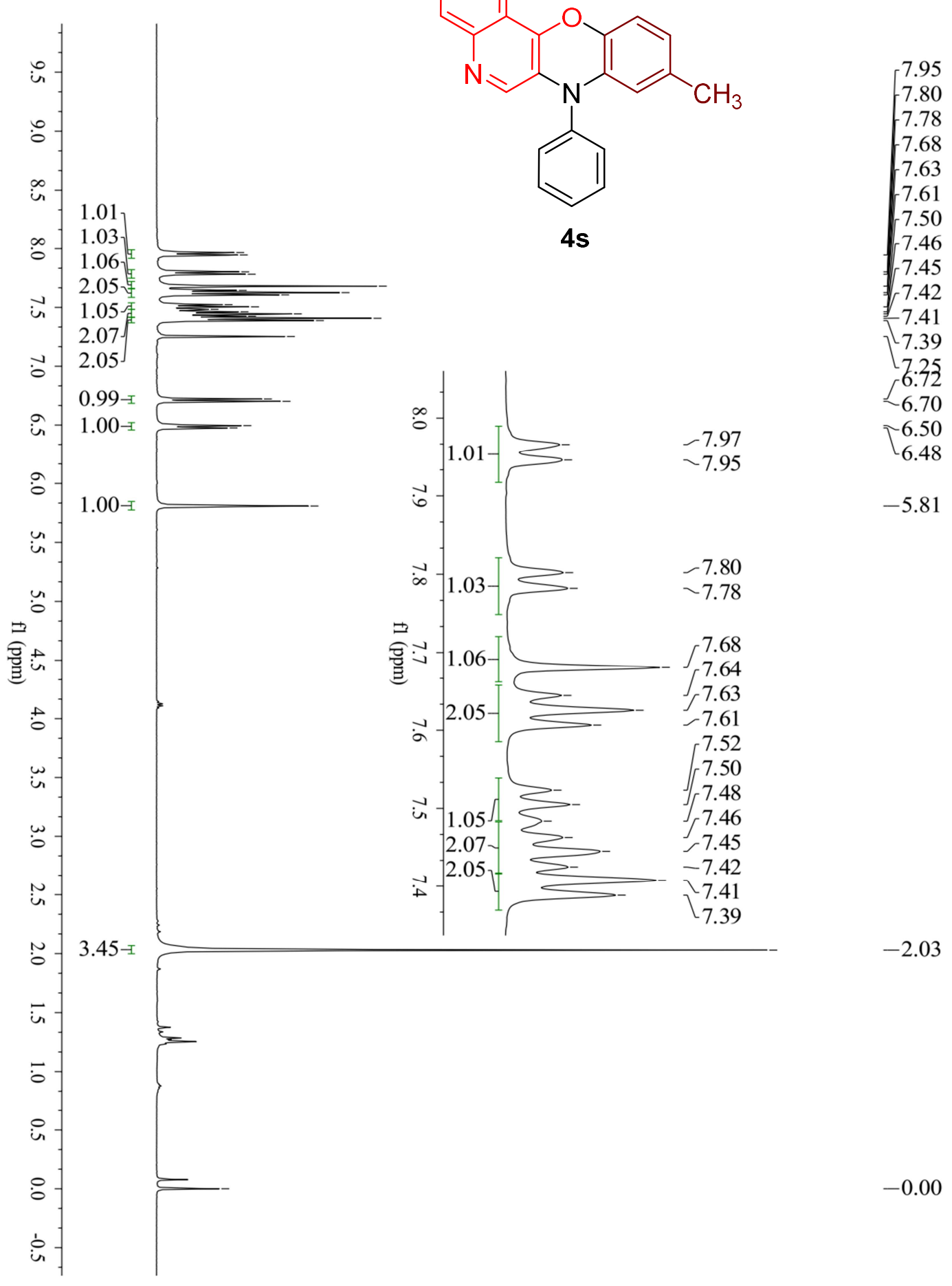


${ }^{13} \mathrm{C}\left\{{ }^{1} \mathrm{H}\right\}$ NMR $\left(101 \mathrm{MHz}, \mathrm{CDCl}_{3}\right)$ spectrum of $\mathbf{4 s}$

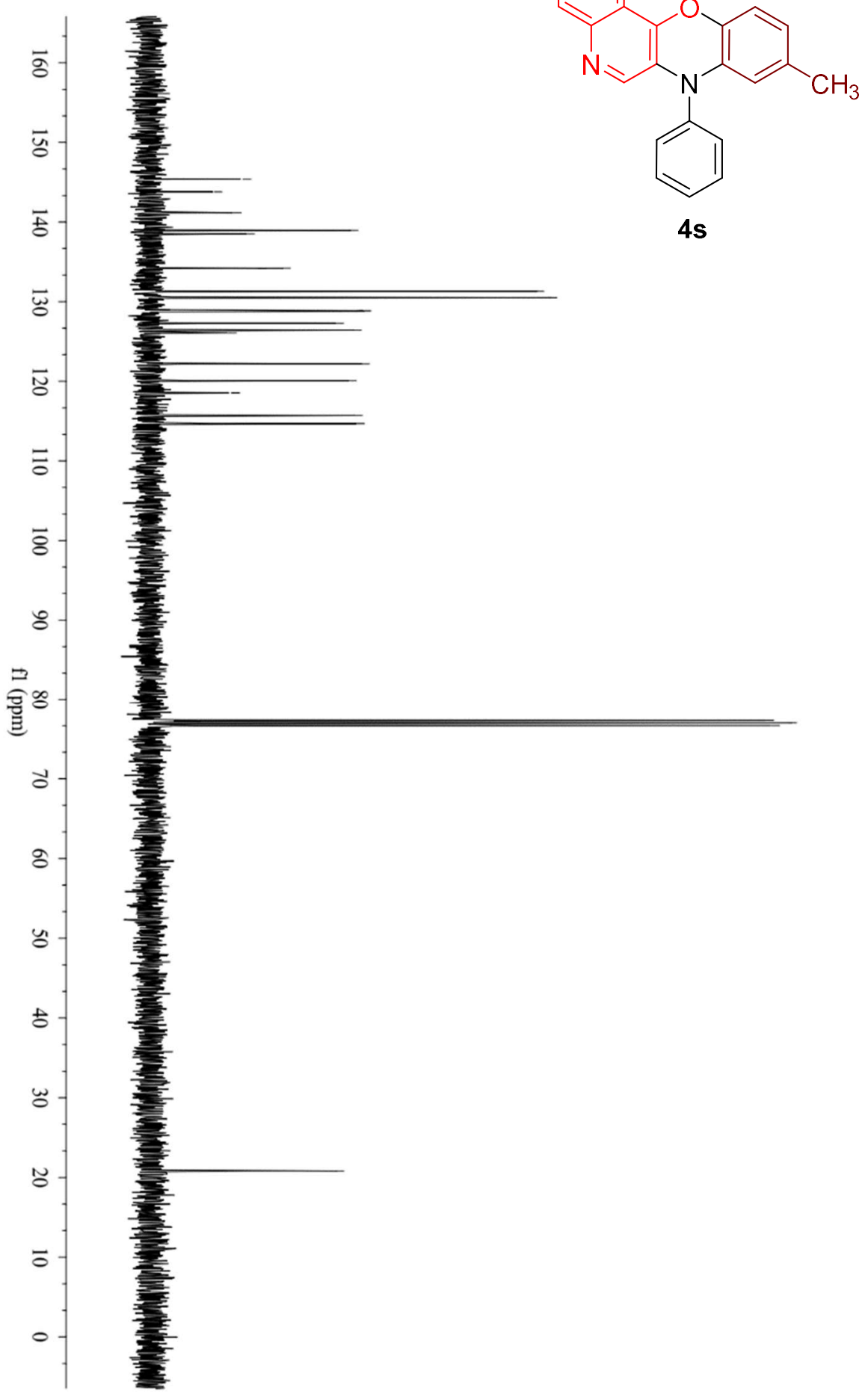

145.37

143.80

141.19

138.95

138.51

134.19

134.16

131.31

130.51

128.85

128.80

127.26

126.39

126.07

122.18

120.09

118.54

115.69

114.68

77.32
-77.00

76.68

$-20.82$ 
${ }^{1} \mathrm{H}$ NMR (400 MHz, $\mathrm{CDCl}_{3}$ ) spectrum of $\mathbf{4 t}$

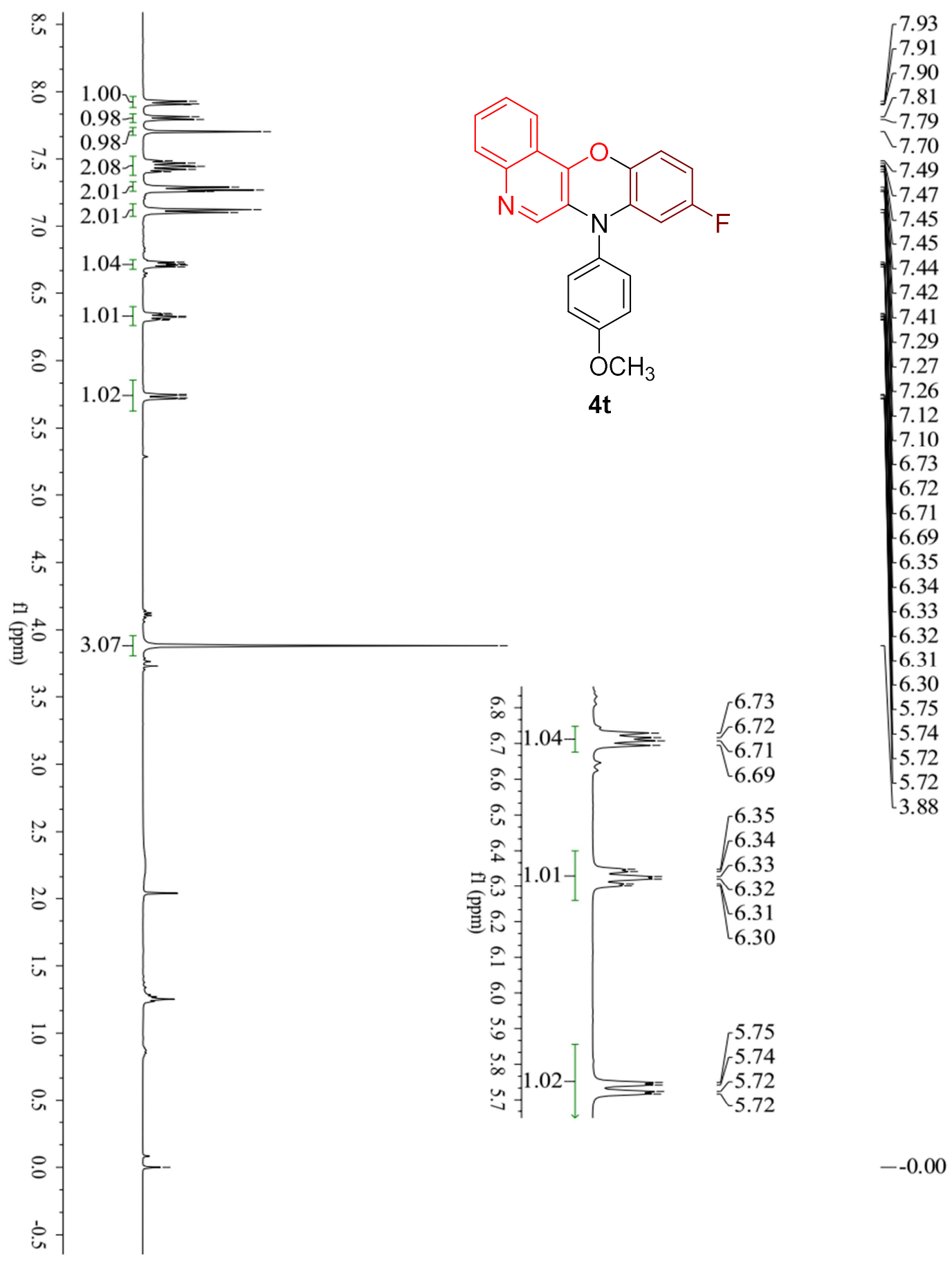


${ }^{13} \mathrm{C}\left\{{ }^{1} \mathrm{H}\right\}$ NMR $\left(101 \mathrm{MHz}, \mathrm{CDCl}_{3}\right)$ spectrum of $\mathbf{4 t}$

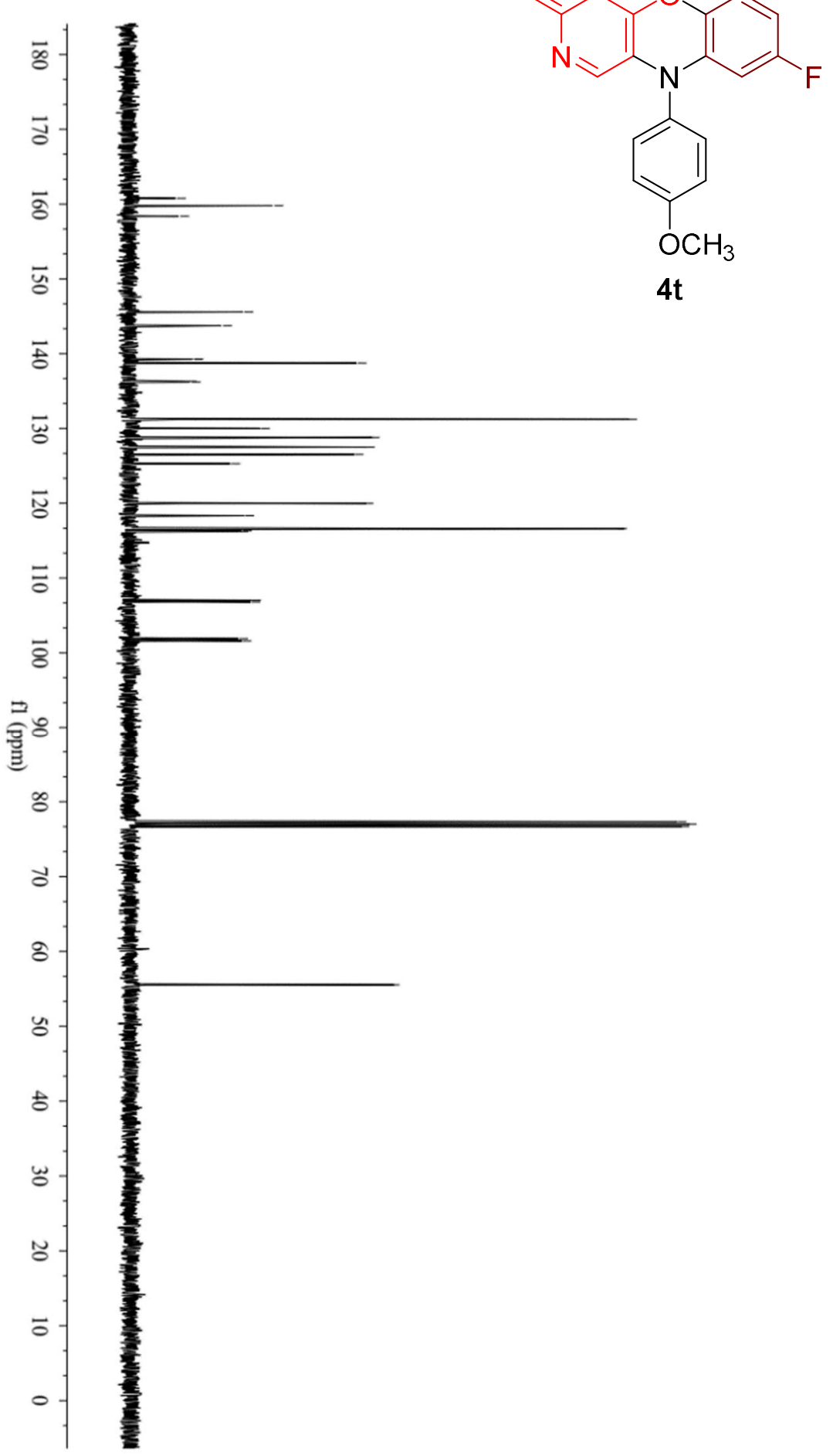

160.77

159.80

158.38

145.58

143.74

139.29

139.26

138.75

136.31

136.20

131.22

129.99

128.79

$-127.51$

126.54

125.29

119.97

118.34

116.61

116.32

116.22

107.03

106.80

101.89

101.59

77.32

$-77.00$

76.68

$-55.54$ 
${ }^{19} \mathrm{~F}$ NMR (376 MHz, $\mathrm{CDCl}_{3}$ ) spectrum of $\mathbf{4 t}$

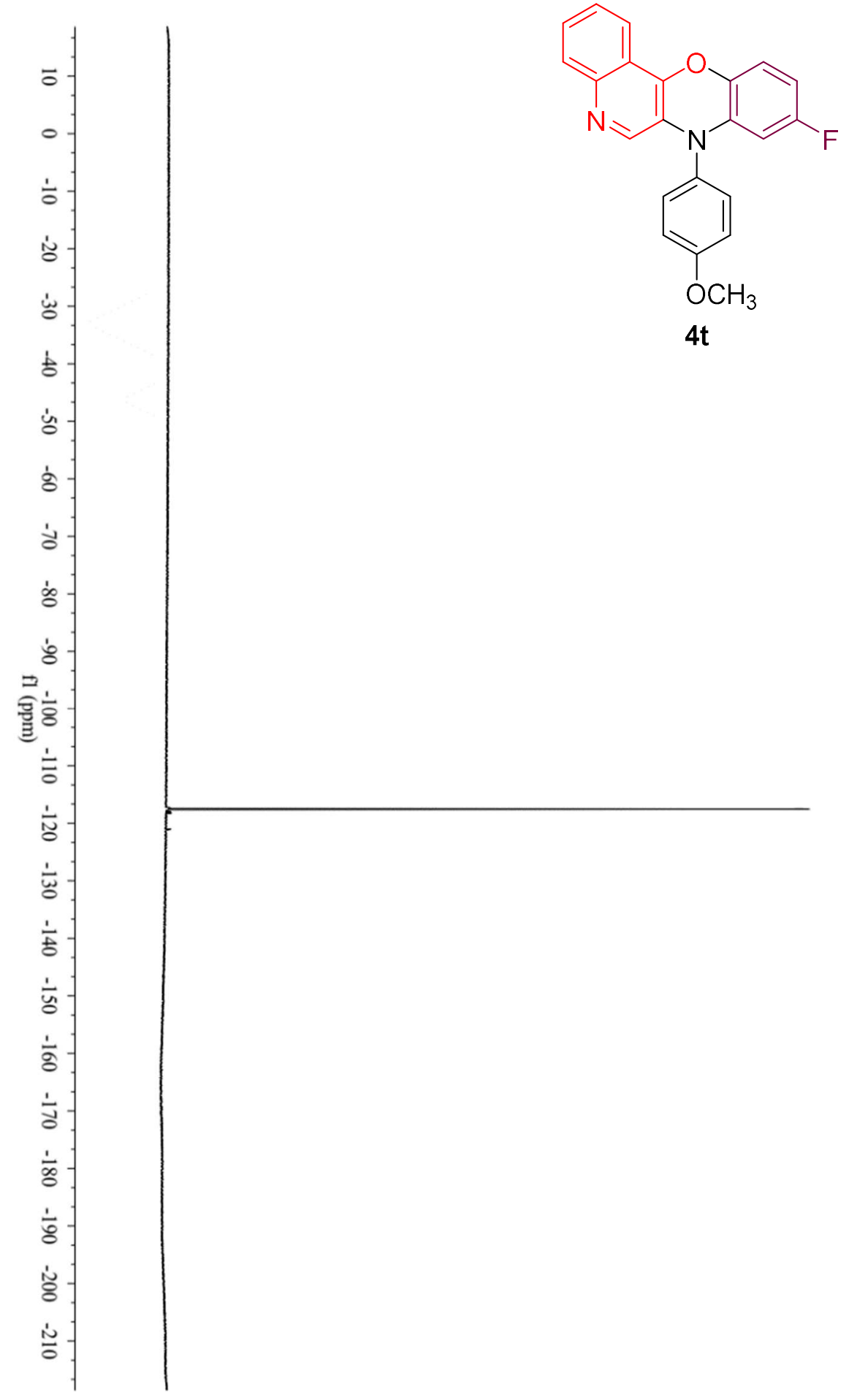

$--117.53$ 
${ }^{1} \mathrm{H}$ NMR $\left(400 \mathrm{MHz}, \mathrm{CDCl}_{3}\right)$ spectrum of $\mathbf{4 u}$
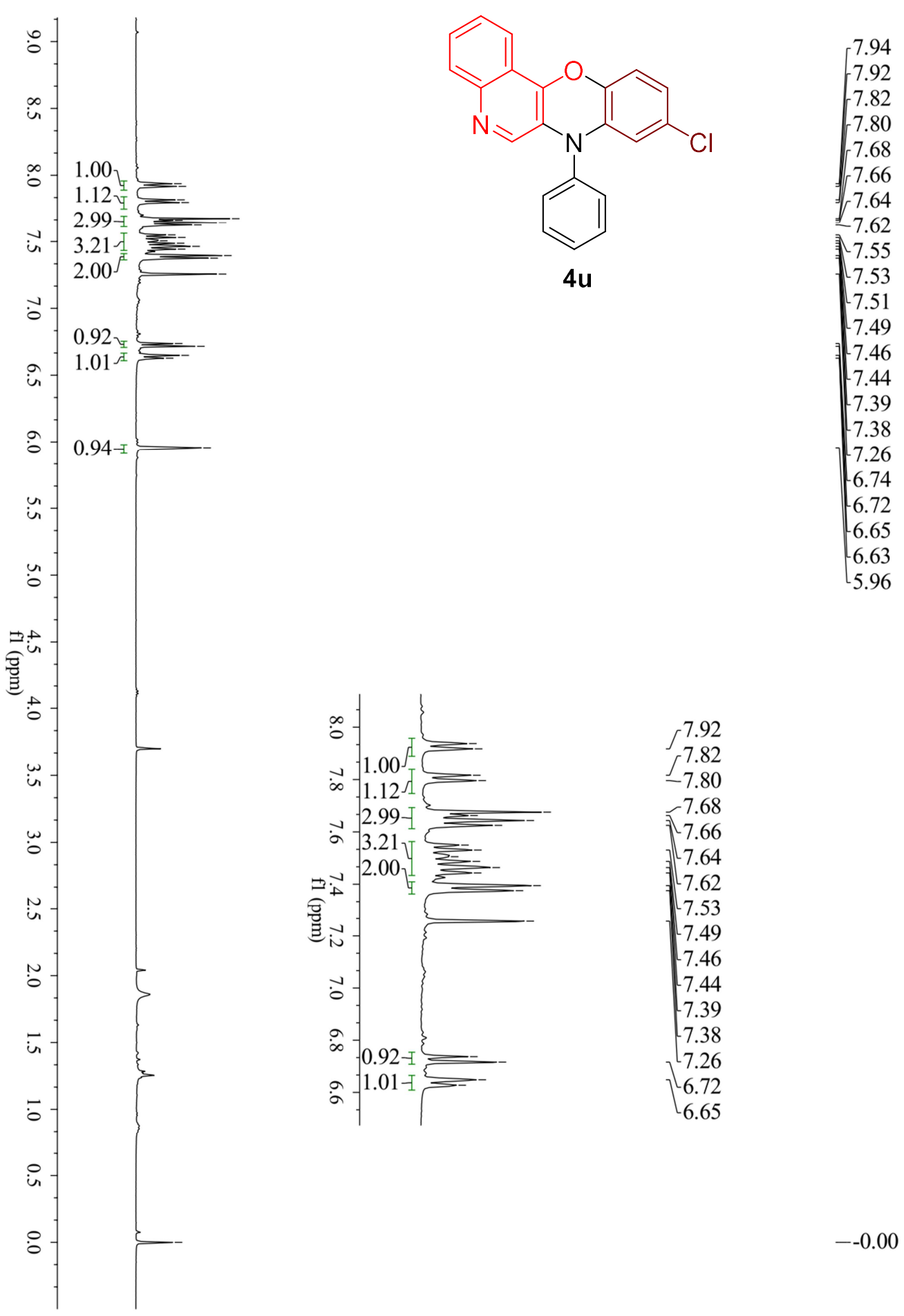

$\left\{\begin{array}{c}7.92 \\ -7.82 \\ -7.80 \\ -7.68 \\ 7.66 \\ 7.64 \\ 7.62 \\ 7.53 \\ 7.49 \\ 7.46 \\ 7.44 \\ 7.39 \\ 7.38 \\ 7.26 \\ 6.72 \\ 6.65\end{array}\right.$ 


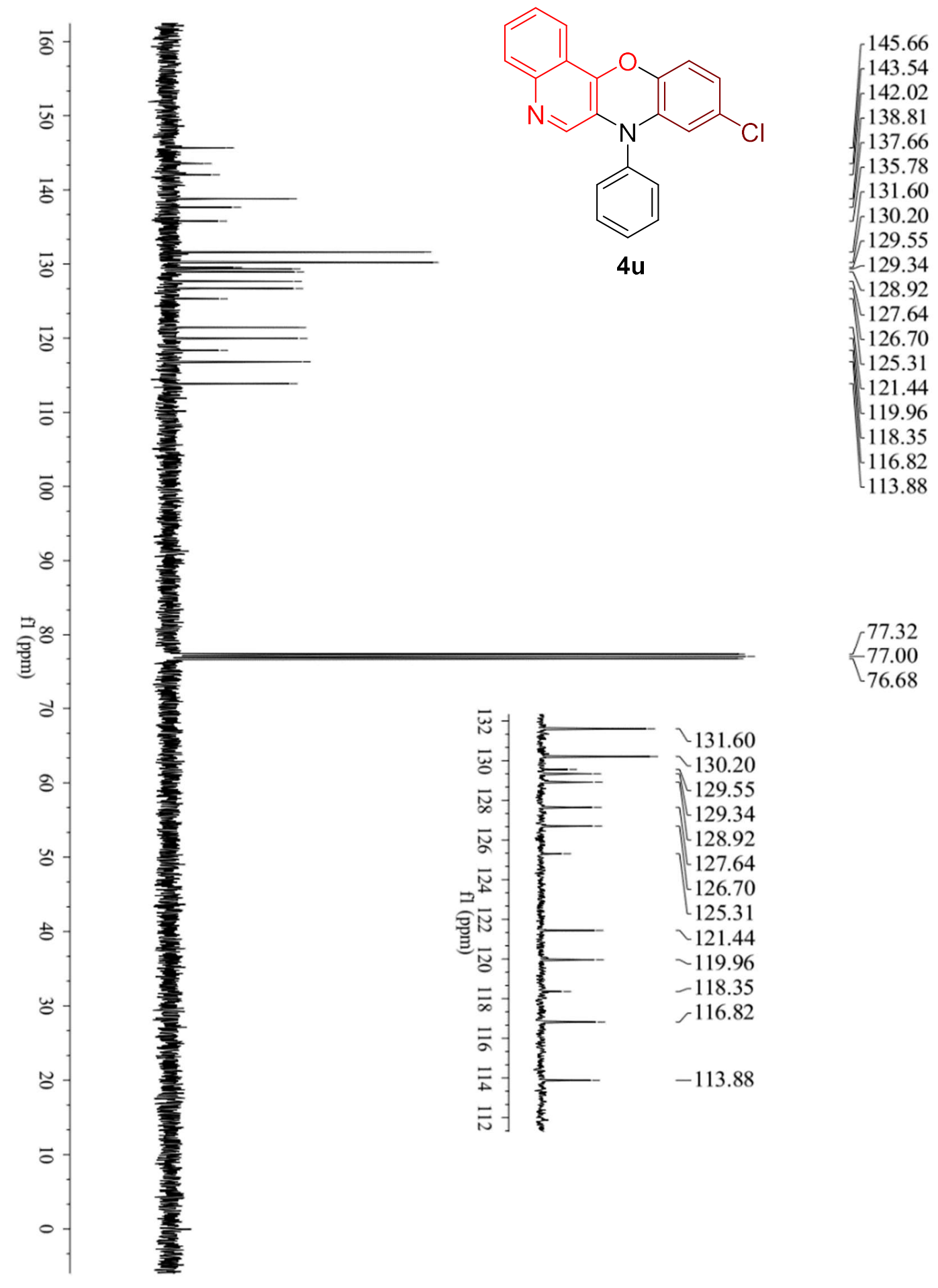


${ }^{1} \mathrm{H}$ NMR (400 MHz, $\left.\mathrm{CDCl}_{3}\right)$ spectrum of $\mathbf{4 v}$
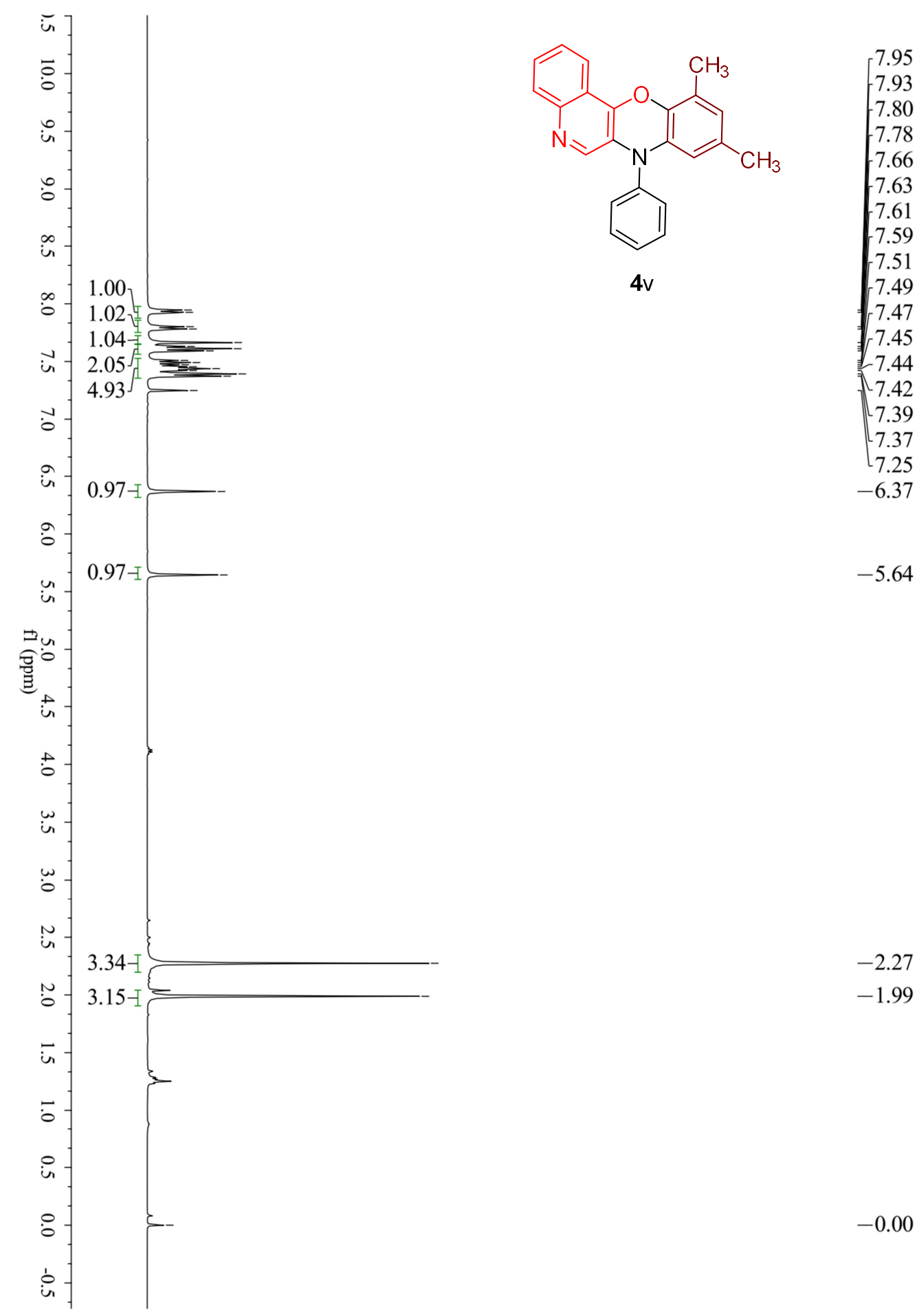

$-2.27$

$-1.99$

$-0.00$ 
${ }^{13} \mathrm{C}\left\{{ }^{1} \mathrm{H}\right\}$ NMR $\left(101 \mathrm{MHz}, \mathrm{CDCl}_{3}\right)$ spectrum of $\mathbf{4 v}$

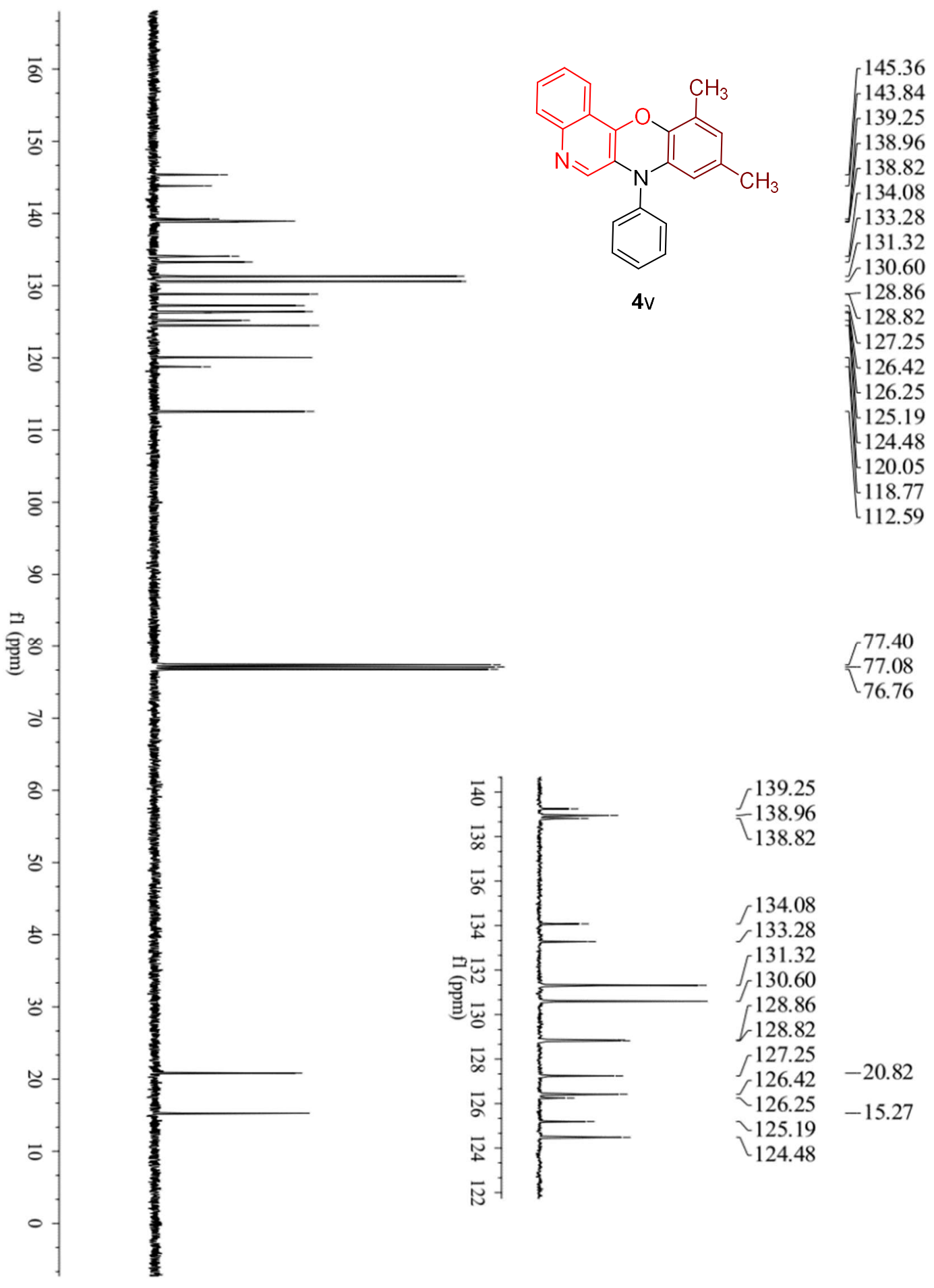


${ }^{1} \mathrm{H} \mathrm{NMR}\left(400 \mathrm{MHz}, \mathrm{CDCl}_{3}\right)$ spectrum of $\mathbf{5 a}$

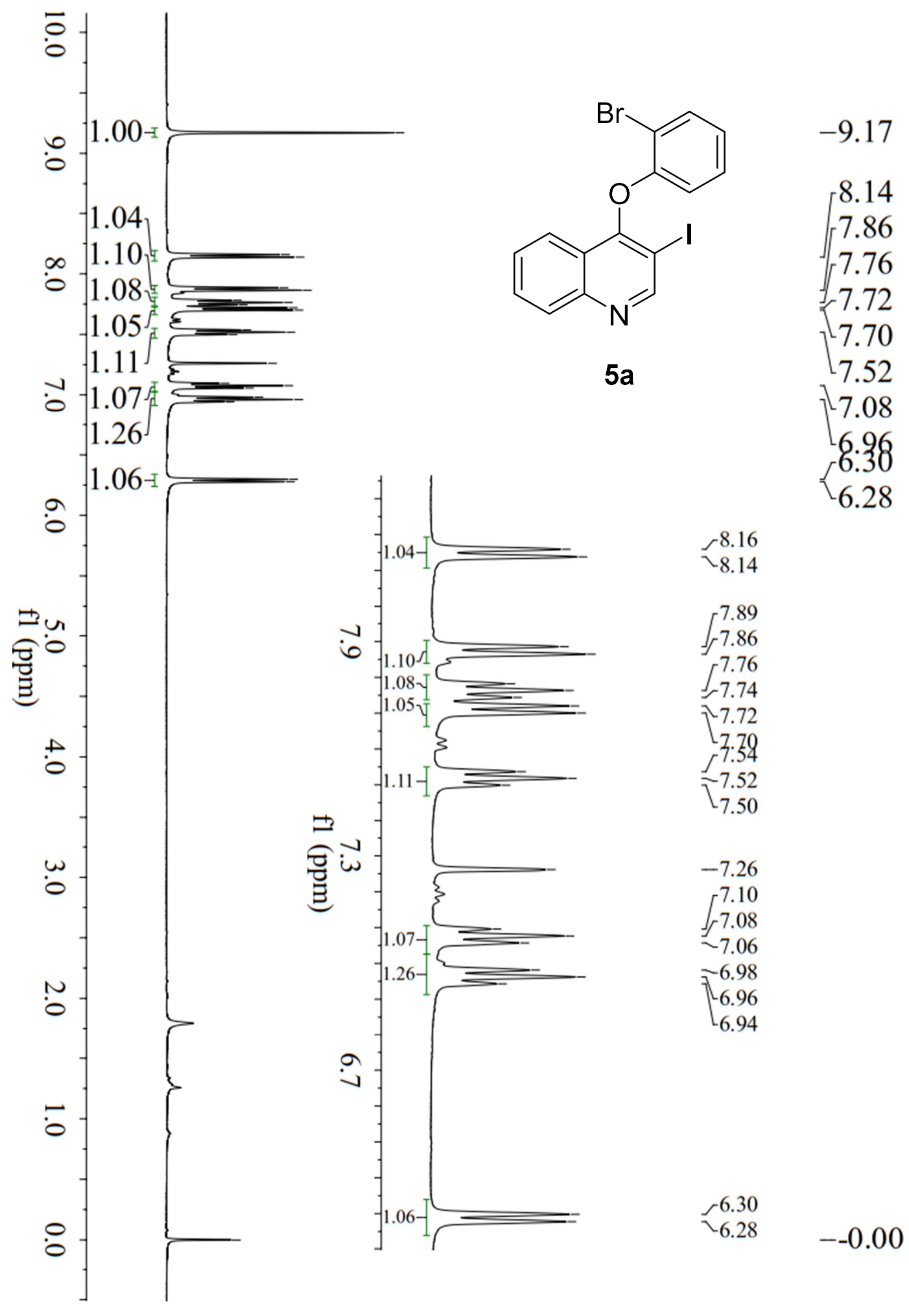


${ }^{13} \mathrm{C}\left\{{ }^{1} \mathrm{H}\right\}$ NMR $\left(101 \mathrm{MHz}, \mathrm{CDCl}_{3}\right)$ spectrum of $\mathbf{5 a}$

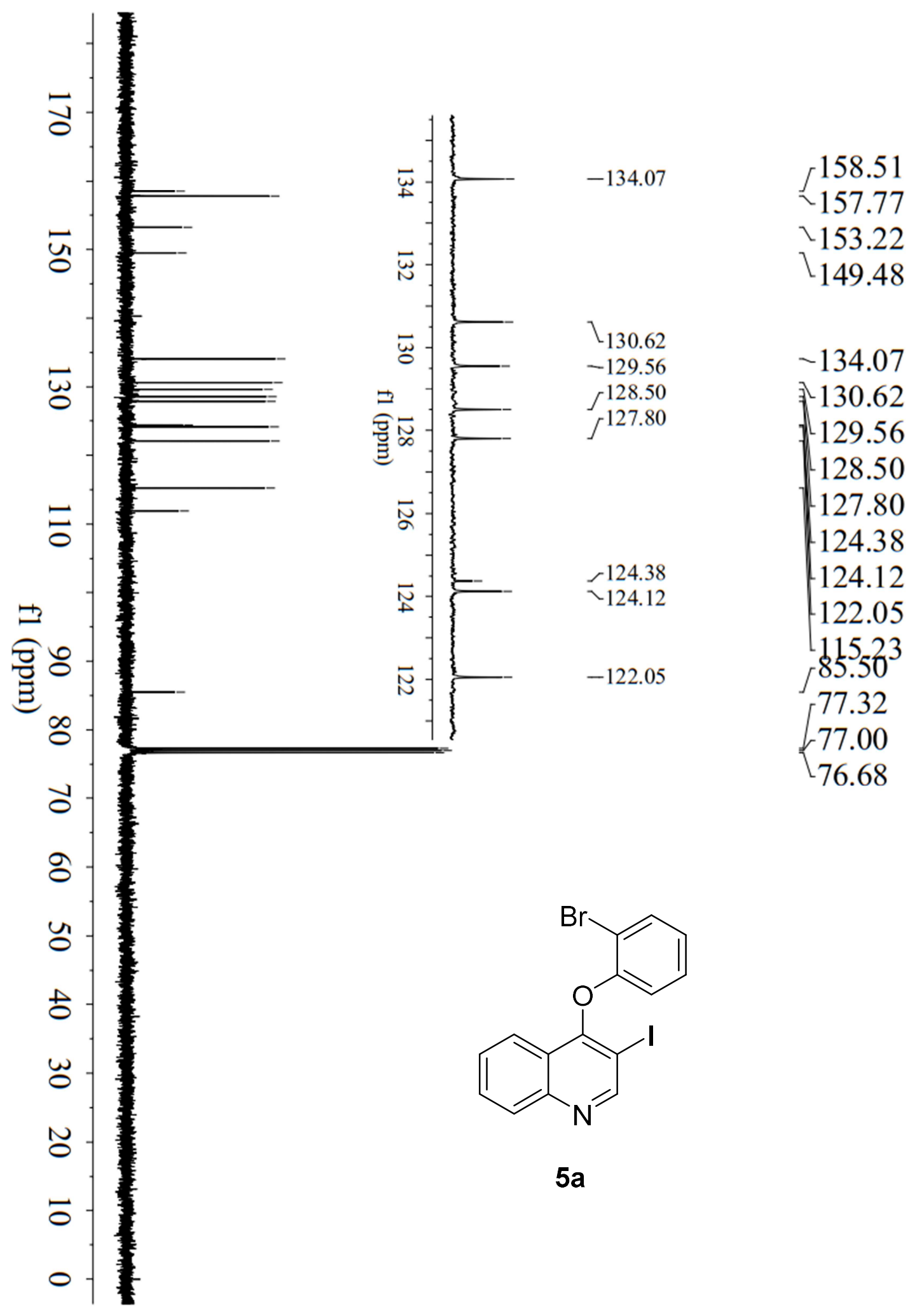


${ }^{1} \mathrm{H}$ NMR (600 MHz, $\left.\mathrm{CDCl}_{3}\right)$ spectrum of $\mathbf{4 a}$ '

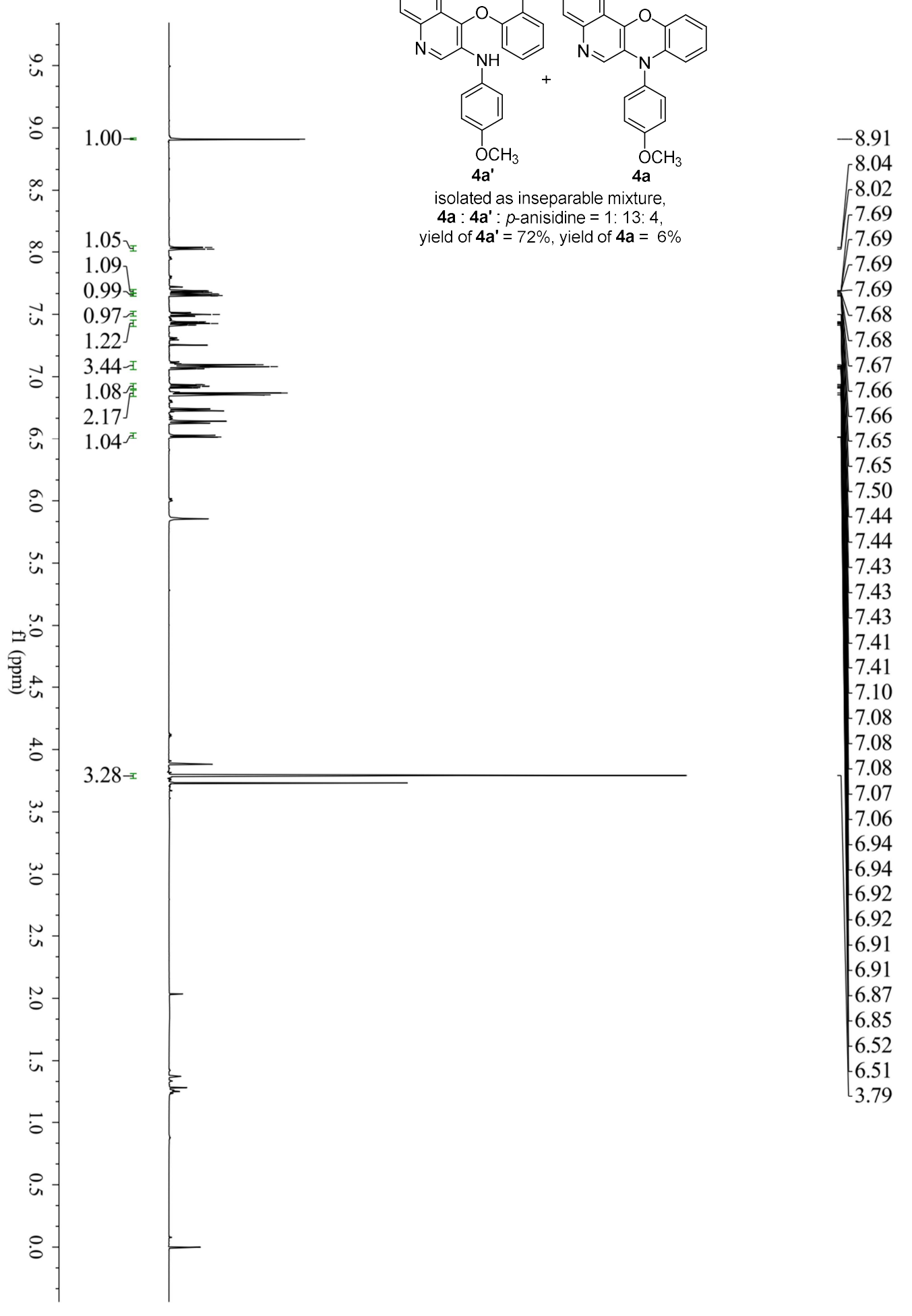


${ }^{1} \mathrm{H}$ NMR $\left(600 \mathrm{MHz}, \mathrm{CDCl}_{3}\right)$ spectrum of $\mathbf{4 a}$ '

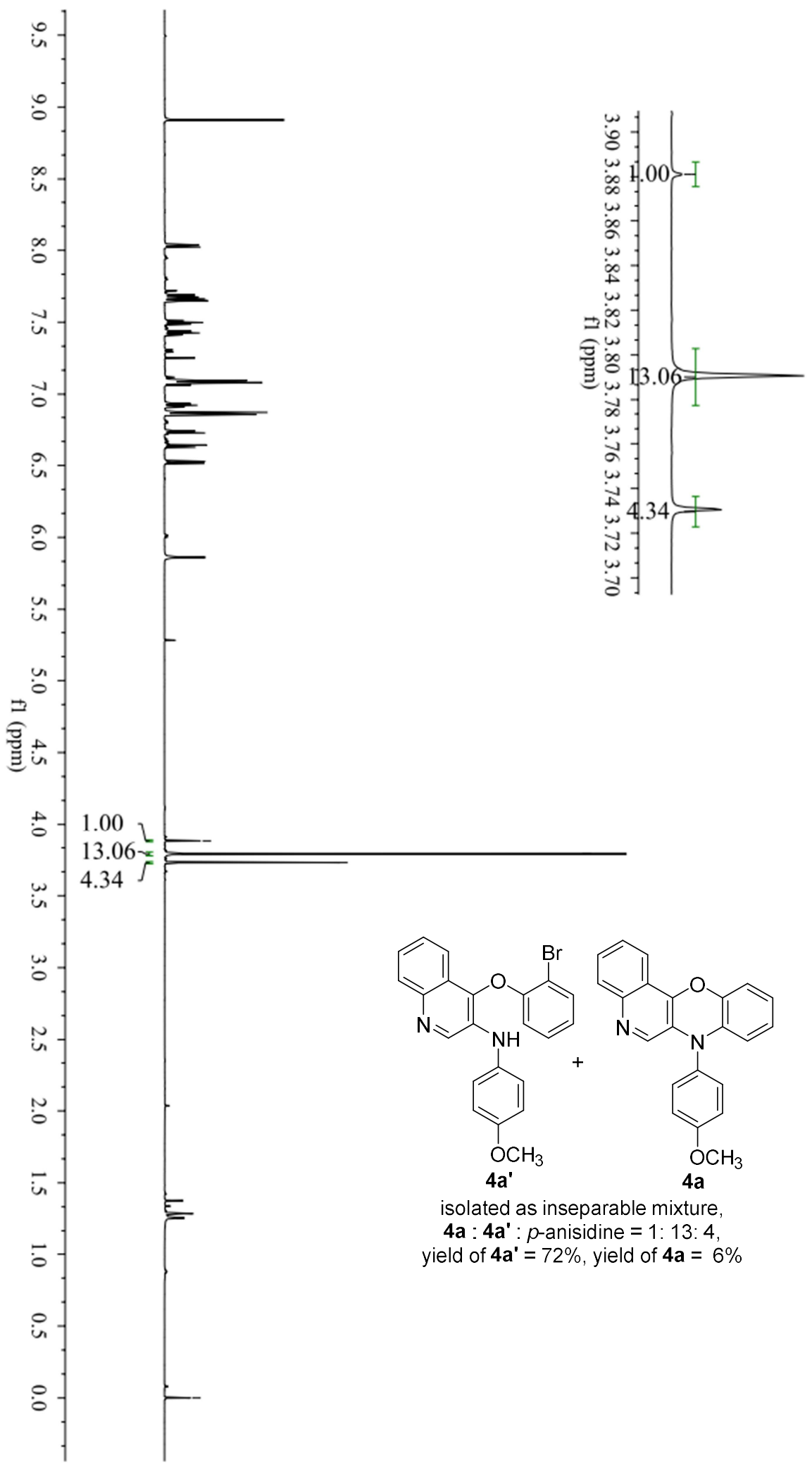




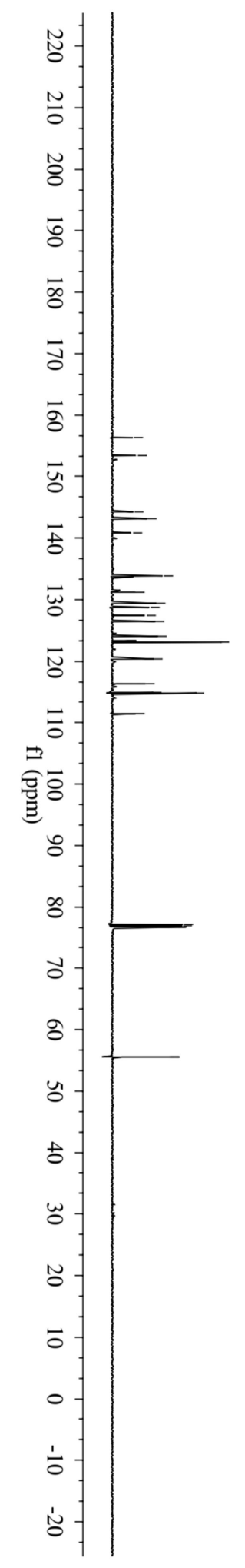

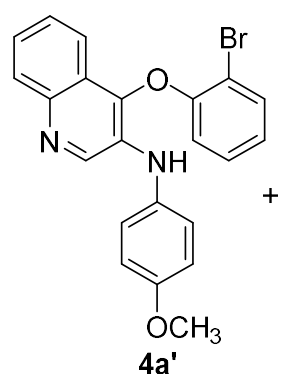<smiles>c1ccc2c(c1)Nc1cnc3ccccc3c1O2</smiles>

$-156.38$

$\mathcal{L}_{143.12}^{144.22}$

$\sim 140.81$

$-133.85$

133.85
-131.20

$-129.41$

128.76

127.45

126.49

$-124.08$

$-123.15$

$-120.40$

115.00

$-114.88$

$-114.81$

111.43

$\left\{\begin{array}{r}77.21 \\ -77.00 \\ 76.79\end{array}\right.$

$-55.54$ 
${ }^{1} \mathrm{H}$ NMR $\left(400 \mathrm{MHz}, \mathrm{CDCl}_{3}\right)$ spectrum of $\mathbf{8 a}$

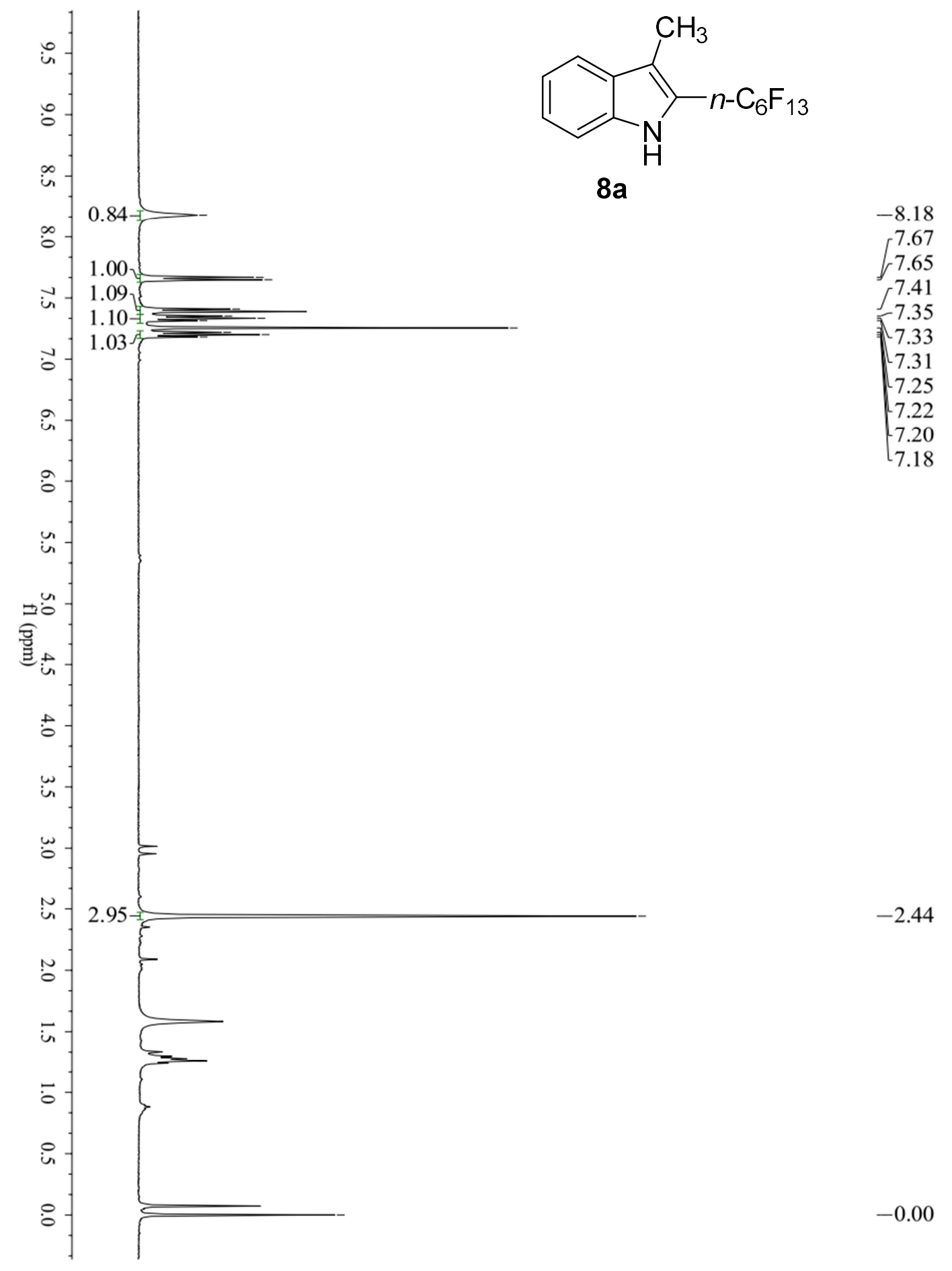


${ }^{19} \mathrm{~F}$ NMR $\left(376 \mathrm{MHz}, \mathrm{CDCl}_{3}\right)$ spectrum of $\mathbf{8 a}$

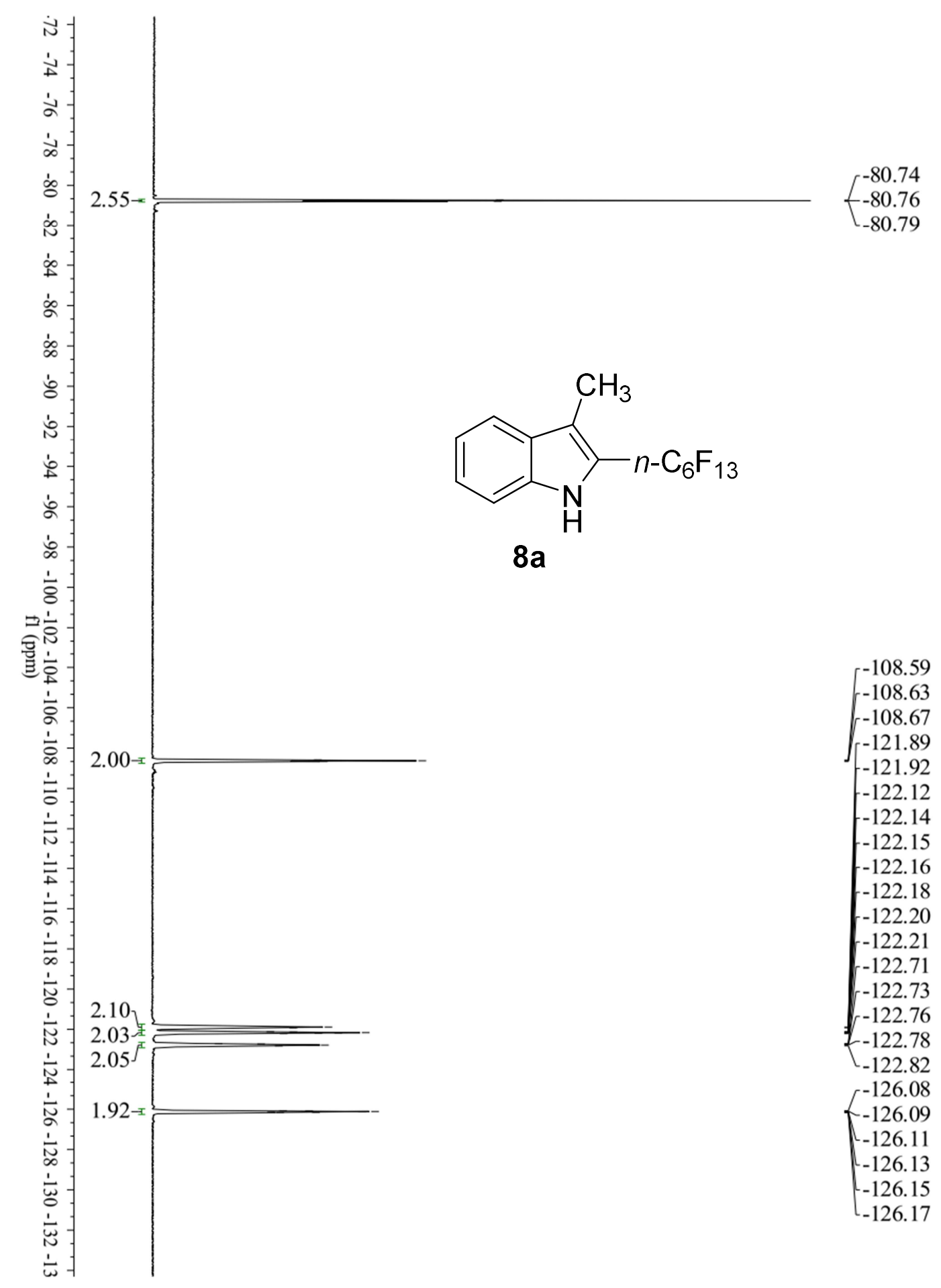


3. NMR and GPC Spectra of the Photoredox-catalyzed Atom Transfer Radical Polymerization
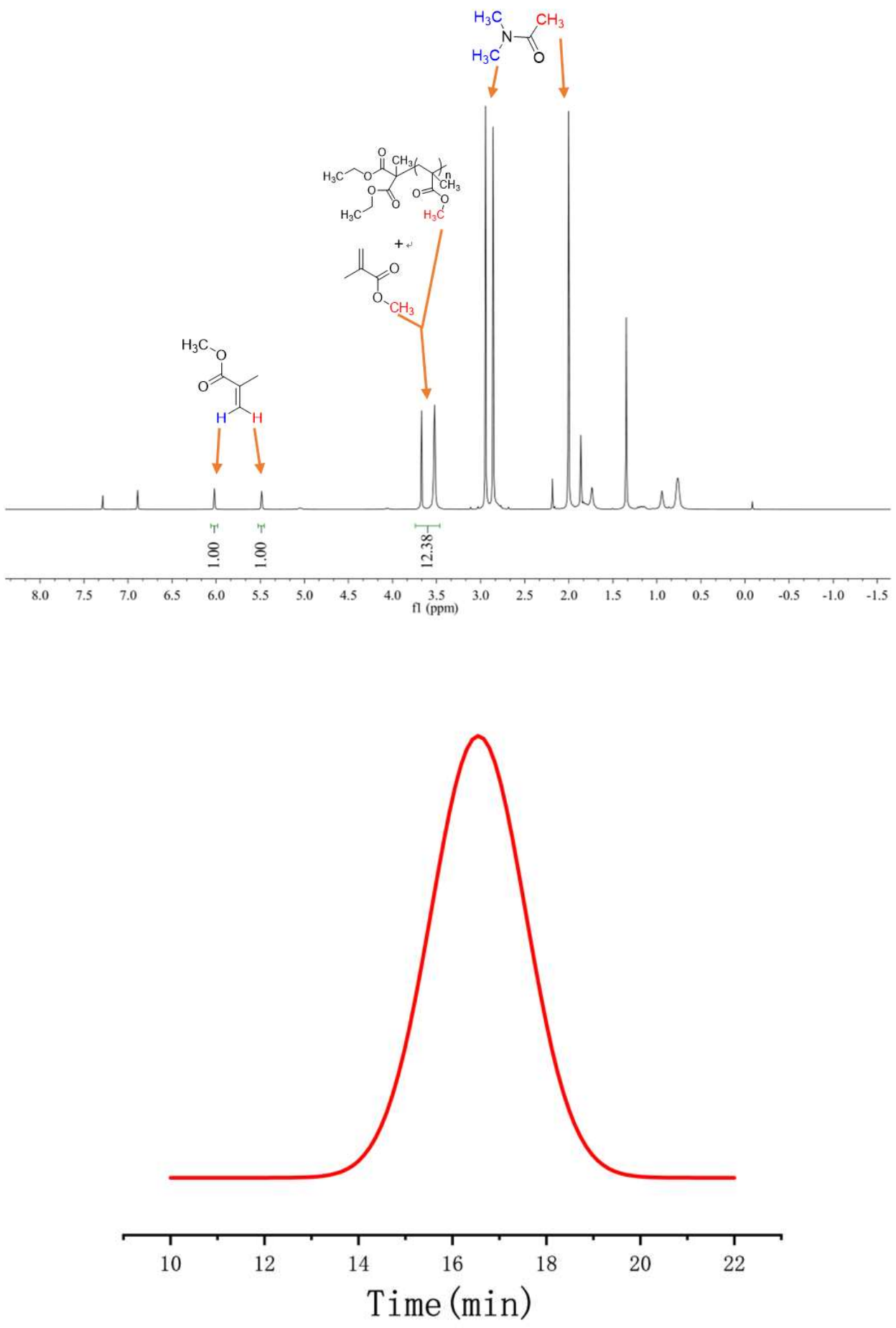